\title{
Financial Crises and Systemic Bank Runs in a Dynamic Model of Banking
}

\author{
Roberto Robatto, ${ }^{*}$ University of Wisconsin-Madison
}

November 28, 2014

\begin{abstract}
I present a new dynamic general equilibrium model of banking to analyze monetary policy during financial crises. A novel channel gives rise to multiple equilibria. In the good equilibrium, all banks are solvent. In the bad equilibrium, many banks are insolvent and subject to runs. The bad equilibrium is also characterized by deflation and a flight to liquidity.

Some central bank interventions are more effective than others at eliminating the bad equilibrium. Interventions that do not eliminate the bad equilibrium still counteract deflation and reduce the losses of insolvent banks, but, for some parameter values, amplify the flight to liquidity.
\end{abstract}

JEL Codes: E44, E52, G01, G21

\section{Introduction}

A peculiar event of the 2007-2009 US financial crisis was a dramatic increase in the private sector's willingness to hold liquid assets, a "flight to liquidity." The Federal Reserve reacted aggressively at the time, implementing unconventional monetary policies. The flight to liquidity and the interventions of the Fed resulted in

*University of Wisconsin-Madison, Wisconsin School of Business, 975 University Avenue, Madison WI 53706. E-mail: rrobatto@ bus.wisc.edu. This paper is based on the main chapter of my Ph.D. dissertation at the University of Chicago. I am grateful to Fernando Alvarez, Veronica Guerrieri, Robert Lucas, and Harald Uhlig for suggestions and guidance, and to Ana Babus, Gadi Barlevy, Philip Barrett, Martin Beraja, Maryam Farboodi, Kinda Hachem, Lars Hansen, Rebecca Myerson, Stefanie Stantcheva, Balázs Szentes, Pietro Veronesi, seminar participants at BFI Financial Markets and Contracts Graduate Student Conference, Chicago Fed, EIEF, Federal Reserve Board, MacroFinancial Modeling Group Meetings, Richmond Fed, University of Chicago, University of Toronto and University of Wisconsin-Madison for comments. I thank the Becker-Friedman Institute and the Macroeconomic Modeling and Systemic Risk Research Initiative for financial support. 
an approximately constant price level and a sizable drop in the money multiplier. ${ }^{1}$ The Great Depression saw a similar drop in the money multiplier. Friedman and Schwartz (1963) argue that the absence of adequate Federal Reserve intervention at that time generated deep deflation, making what would otherwise have been a modest or deep recession the Great Depression.

During both these crises, several financial institutions became insolvent and were subject to runs. More than one-fifth of the commercial banks in the US suspended operations during the Great Depression (Friedman and Schwartz, 1963). The collapse of Lehman Brothers in September 2008 was followed by a "run on repo" and on other institutions not covered by deposit insurance, as Gorton and Metrick (2012a,b) document.

Motivated by these events, the first contribution of this paper is to provide a new dynamic general equilibrium model of banking with multiple equilibria. The multiplicity of equilibria is based on a debt-deflation channel similar to Fisher (1933), a novel approach in the panic-based bank runs literature. In the good equilibrium, all banks are solvent. In the bad equilibrium, many banks are insolvent and subject to runs. Distress in the banking sector is associated with deflation, a drop in asset prices, and a flight to liquidity (that is, depositors hold more money and fewer deposits at banks, in comparison to the good equilibrium). In the model, runs and insolvencies are systemic events, in the sense that many financial institutions are subject to distress at the same time. Therefore, the model captures the systemic nature of financial crises.

The second contribution is an application of the model to analyze some of the monetary policies used during the recent US financial crisis. In the model, a central bank can inject money into the economy by either 1) buying assets on the market (asset purchases), or 2) setting up liquidity facilities (in order to provide loans to banks). Using numerical simulations of the model, I show that both asset purchases and loans to banks counteract deflation, reduce the losses of insolvent banks, and if the intervention of the central bank is sufficiently large, eliminate the bad equilibrium. This result is consistent with the Friedman-Schwartz hypothesis regarding

\footnotetext{
${ }^{1}$ The money multiplier is the ratio of broad monetary aggregates, such as M1 or M2, to the monetary base M0.
} 
the Great Depression. In addition, there are two novel results. First, in some circumstances loans to banks eliminate the bad equilibrium while asset purchases do not. Second, for some parameter values, if a temporary monetary injection does not eliminate the bad equilibrium, it amplifies the flight to liquidity.

In the model, households are subject to uninsurable preference shocks that affect the utility of consumption, similarly to Diamond and Dybvig (1983). There is an exogenous supply of two assets in the economy, fiat money and a productive asset (capital). Trading frictions interact with the timing of preference shocks and create a precautionary demand for money to finance consumption expenditure.

Banks offer deposits in order to provide money to households on demand. In the model, banks are unregulated institutions that perform maturity transformation without deposit insurance, similar to commercial banks in the 1930s and to the shadow banking system in recent years.

In the banking sector, two frictions are crucial. First, deposits are nominal, i.e., specified in terms of money. Second, capital held by banks is hit by idiosyncratic shocks (in particular, I will consider one-time unanticipated shocks). For an individual bank, a negative shock destroys some of its capital, while a positive shock increases its stock of capital. Since the shocks are idiosyncratic, the aggregate stock of capital is constant. Crucially, there is asymmetric information about the shocks. Each bank observes its own shock, but it takes time for other banks and households to observe them. Thus, households do not know whether their own bank has been hit by a positive or a negative shock. ${ }^{2}$

In a steady-state with no shocks to banks, deposits overcome the frictions that give rise to the precautionary demand for money. When the one-time unanticipated shocks hit banks, a good equilibrium always exists wherein all banks are solvent (including banks hit by a negative shock) and the banking sector functions normally as in steady-state. A bad equilibrium exists for a large subset of the parameter space. The bad equilibrium lasts one period and then the economy reverts to normal. However, the model can be extended so that the bad equilibrium lasts many periods.

A bad equilibrium is characterized by three features. First, the economy expe-

\footnotetext{
${ }^{2}$ Gorton (2008) emphasizes the uncertainty regarding the identities of the financial institutions that incurred significant losses associated with the housing market during the Great Recession.
} 
riences deflation and a drop in the nominal price of capital. Second, a bank hit by a negative shock becomes insolvent; the value of capital drops due to the drop in its nominal price and to the negative idiosyncratic shock, while liabilities (deposits) are in nominal terms and thus constant (debt-deflation). Banks hit by a positive shock remain solvent. Asymmetric information prevents depositors from immediately identifying insolvent banks, but eventually, the insolvency of banks becomes common knowledge and insolvent banks are subject to runs. Third, anticipating the possibility of runs, households hold more money and fewer deposits due to the precautionary demand for money (flight to liquidity).

This scenario is an equilibrium because there is a general equilibrium feedback from the flight to liquidity to the drop in prices. With the flight to liquidity, some money is stored under the mattress for precautionary reasons, therefore less money is in circulation for transactions. As a result, the price level drops because it is proportional to the amount of money used for transactions, an argument related to the quantity theory of money. Because of the drop in the price of consumption goods, the asset that produces such goods (capital) is less valuable, and its price drops as well. Deflation occurs (or, more generally, lower-than-anticipated inflation), because all the money is spent in the pre-crisis period and in the good equilibrium.

As deposits are assets that can be converted easily into money, they are part of broad monetary aggregates such as M1. The drop in deposits is therefore equivalent to a drop in M1 and thus in the money multiplier (due to a constant money supply).

Within the category of bad outcomes there are actually multiple bad equilibria, more precisely up to three bad equilibria depending on parameters. One bad equilibrium cannot be extended to multi-period crises. The other two bad equilibria can instead be extended to multi-period crises, and I focus most of my analysis on these two. The multiplicity of bad equilibria arises from a strategic complementarity across depositors. That is, if everybody else reduces deposits at banks, an individual depositor wants to do the same.

The first novel result related to monetary policy is a comparison between the ability of loans to banks and of asset purchases to eliminate the bad equilibria. Both policies are successful if monetary injections target a high enough threshold for the price level. If the central bank does not target the threshold price (perhaps 
due to considerations not captured by the model such as other welfare costs or legal restrictions) the result is more complicated. Asset purchases do not eliminate the bad equilibria, while a moderate monetary injection implemented using loans to banks is successful. It is, however, crucial that loans to banks have the same seniority as deposits. ${ }^{3}$ Thus, losses of insolvent banks are borne not only by depositors, but also by the central bank, so households are willing to hold more deposits. With equal seniority, the central bank suffers losses on loans to banks that go bankrupt, even though just off-equilibrium. Crucially, this policy also eliminates the strategic complementarity that gives rise to multiple bad equilibria.

The second monetary policy result is related to monetary injections that do not eliminate the bad equilibria and that are temporary (i.e., the money supply reverts to the pre-crisis level when the panic ceases). For some parameter values, both loans to banks and asset purchases reduce the equilibrium value of deposits, exacerbating the flight to liquidity. Moreover, if without policy intervention there exists only one bad equilibrium, some monetary injections give rise to a further bad equilibrium, in which the flight to liquidity is exacerbated even more. Due to this endogenous amplification, the conclusions of monetary policy analysis may differ from models in which the flight to liquidity is caused by exogenous shocks to money demand (such as Allen et al., 2013, Christiano et al., 2003, and Diamond and Rajan, 2006). This possible amplification of the flight to liquidity is the result of two counteracting effects. First, monetary policy pushes the equilibrium outcome closer to what would prevail if agents did not panic, stabilizing the economy and reducing the flight to liquidity. Second, money injections increase demand for capital regardless of whether the central bank buys capital directly (asset purchases) or gives loans to banks. In the latter case, demand for capital increases because private banks increase purchases of capital after receiving loans. This higher demand increases the price of capital and thus reduces its return. Since banks invest part of their deposits in capital, the drop in the return on capital implies a drop in the return that banks pay to depositors, thereby making depositors less willing to hold deposits. This second mechanism counteracts the first stabilizing force, and the total effect on the

\footnotetext{
${ }^{3}$ Seniority refers to the order of repayment in the event of bankruptcy. Senior debts are repaid first during bankruptcy, while other junior debts are repaid thereafter, if residual funds remain.
} 
equilibrium value of deposits is ambiguous.

\subsection{Comparison with the literature}

Diamond and Dybvig (1983) formalize the notion of bank runs as panics, using multiplicity of equilibria. There are a number of differences between Diamond and Dybvig (1983) and my work. First, there is only one real asset in Diamond and Dybvig (1983), so it is difficult to use their model to analyze monetary injections. In contrast, my model has a specific role for money. ${ }^{4}$ Second, the model of Diamond and Dybvig (1983) has exogenous asset returns, and thus is often interpreted as a partial equilibrium model of one bank. My analysis is instead based on a general equilibrium model with endogenous returns, and runs are systemic events that involve a fraction of the banking system. Third, the run equilibrium in Diamond and Dybvig (1983) relies on a coordination failure with regard to the decision to run-not run. In my model, the bad equilibrium is instead based on a debt-deflation channel, and the coordination failure is based on the decision to fly-not fly to liquidity.

Angeloni and Faia (2013), Ennis and Keister (2003), Gertler and Kiyotaki (2013), Martin et al. (2011), and Mattana and Panetti (2014) combine three-period models of runs with the infinite-horizon formulation of business cycle models. The work of Gertler and Kiyotaki (2013) is closely related to mine; multiple equilibria are due to a general equilibrium channel, and crises are systemic. Differently, they do not include money or information asymmetries, and there are runs on all banks rather than just on a fraction of the banking system as in my model.

The models of Carapella (2012) and Cooper and Corbae (2002) are also closely related to mine. Both present monetary models with multiple equilibria, but their focus is on banking intermediation rather than insurance against liquidity risk and runs. In Carapella (2012), multiplicity arises due to a debt-deflation channel similar to my paper. Policy analysis, however, emphasizes the comparison between monetary injections and deposit insurance, rather than among alternative monetary policy tools. In Cooper and Corbae (2002), multiplicity is related to increasing returns to scale in intermediation, and monetary policy eliminates the bad equilibrium

\footnotetext{
${ }^{4}$ Other papers such as Allen et al. (2013) and Diamond and Rajan (2006) include money in models of banking, but their focus is different from panic-based runs.
} 
by increasing the growth rate rather than increasing the level of money.

Several studies analyze banks in markets with asymmetric information (see e.g., Freixas and Rochet, 2008), and a recent literature incorporates them into dynamic general equilibrium models (e.g., Bigio, 2012, Boissay et al., 2013, and MartinezMiera and Suarez, 2012).

The assumptions concerning the structure of trading in my model are very similar to Telyukova and Visschers (2013) and are also analogous to Bianchi and Bigio (2013), Lagos and Wright (2005), and Lucas (1990).

Other papers focus on similar aspects of financial crises and policies as mine, but use alternative models. In Brunnermeier and Sannikov (2011), a shock to financial intermediaries triggers debt deflation; monetary policies can help bank recapitalization, but no financial institution is insolvent. In Caballero and Krishnamurthy (2005, 2008), Knightian uncertainty is responsible for a flight to quality. Krishnamurthy (2010) analyzes the role of policy (including monetary policy) to counteract balance sheet amplification and Knightian uncertainty.

Bank runs and the role of asymmetric information have also been analyzed from an empirical standpoint. For the 2008 financial crisis, runs on the "shadow banking system" are discussed by, e.g., Brunnermeier (2009), Duffie (2010), Gorton and Metrick (2012a,b), and Lucas and Stokey (2011), although the debate about their importance is still open (see Krishnamurthy et al., 2012, and Krishnamurthy and Nagel, 2013). Ivashina and Scharfstein (2010) document runs by borrowers who drew down their credit lines. Bank runs are studied by Friedman and Schwartz (1963) for the Great Depression, and by Gorton (1988) for the national banking era (1863-1914). Asymmetric information about banks in the Great Recession is discussed by, e.g., Gorton (2008), and can be inferred also from indirect evidence. Bernanke (2010) and Armantier et al. (2011) emphasize the stigma associated with borrowing from the discount window. A stigma was also associated with banks that borrowed from the government-established RFC (Reconstruction Finance Corporation) in 1932, according to Friedman and Schwartz (1963). Information asymmetries were also important in nineteenth-century banking panics (Gorton and Mullineaux, 1987). 


\section{Model}

The economy is populated by a unit mass of banks indexed by $b \in \mathbb{B} \equiv[0,1]$ and a double continuum of households indexed by $h \in \mathbb{H}=[0,1] \times[0,1]$. I use $i \in \mathbb{B} \cup \mathbb{H}$ as an index that denotes both households and banks.

Time is discrete, and each period is divided into two parts, day and night. I use capital letters to denote quantities and prices during the day, and lower-case letters to denote quantities and prices at night. Superscripts $h$ and $b$ refer to household $h$ and bank $b$.

The Online Appendix A describes an extension to the model that produces a well-defined steady-state. ${ }^{5}$ As the extension does not affect the main results of the paper, I postpone it to the Appendix for simplicity.

\subsection{Households and banks}

Household $h \in \mathbb{H}$ enjoys utility from goods $c_{t}^{h}$ consumed at night according to:

$$
\mathbb{E}_{0} \sum_{t=1}^{\infty} \beta^{t} \varepsilon_{t}^{h} \log c_{t}^{h}
$$

where $\varepsilon_{t}^{h}$ is a preference shock realized at the beginning of the night and:

$$
\varepsilon_{t}^{h}= \begin{cases}\bar{\varepsilon}>0 & \text { (impatient) } \quad \text { with probability } \kappa \\ \underline{\varepsilon}=0 & \text { (patient) } \quad \text { with probability } 1-\kappa\end{cases}
$$

The preference shock is private information of household $h$, is i.i.d. over time and across households, and the law of large numbers holds for each subset of $\mathbb{H}$ with a continuum of households. I impose the normalization:

$$
\mathbb{E}\left(\varepsilon_{t}\right)=1
$$

Therefore, equations (1) and (2) imply $\kappa \bar{\varepsilon}=1$.

\footnotetext{
${ }^{5}$ The Online Appendix is available at: https://sites.google.com/site/ robertorobatto/papers/Robatto_Runs_Online_Appendix.pdf.
} 
The banking sector is perfectly competitive, and the objective of banks is to maximize profits.

\subsection{Assets, trading and shocks to capital}

Assets. There are three assets in the economy: capital, money, and deposits. Capital is in fixed supply $\bar{K}$. The supply of money $M_{t}$ is chosen by the central bank and $M_{t}=\bar{M}$ for all $t .^{6} \mathrm{~A}$ deposit issued by bank $b$ is a claim that is redeemable on demand at bank $b$. The supply of deposits is endogenously determined in equilibrium.

Markets. Trading takes place in a day market and in a night market, as represented in Figure 1.

During the day, there is a Walrasian market in which households and banks trade capital, money, and deposits. The price of money is normalized to one, and $Q_{t}$ is the price of one unit of capital. Let $K_{t}^{i}, M_{t}^{i}$, and $D_{t}^{i}$ be the amount of capital, money, and deposits that agent $i \in \mathbb{H} \cup \mathbb{B}$ has after leaving the day market.

After the day market closes, capital produces output with a linear technology $y(K)=Z K, 0<Z<\infty$. Total output $y(\bar{K})=Z \bar{K}$ is the only consumption good in the economy. There is no depreciation.

At night, there is another centralized market in which household $h \in \mathbb{H}$ can buy consumption goods $c_{t}^{h}$ at price $p_{t}$, subject to a cash-in-advance constraint. ${ }^{7}$ Capital cannot be traded at night. Let $m_{t}^{i}$ and $d_{t}^{i}$ be the amount of money and deposits of agent $i \in \mathbb{H} \cup \mathbb{B}$ at the end of the night (to be defined later).

State variables and shocks to capital Each agent $i \in \mathbb{H} \cup \mathbb{B}$ starts the day with a vector of state variables $\boldsymbol{X}_{t}^{i}$ :

$$
\boldsymbol{X}_{t}^{i}=\left\{\left(K_{t-1}^{i}, m_{t-1}^{i}, d_{t-1}^{i}\right), \psi_{t}^{i}\right\}
$$

\footnotetext{
${ }^{6}$ The assumption $M_{t}=\bar{M}$ is relaxed in Section 5 in the discussion of monetary policy.

${ }^{7}$ Households cannot consume output produced by their own stock of capital, similarly to standard models with a cash-in-advance constraint such as Lucas and Stokey (1987). Online Appendix B.1 provides more discussion about the cash-in-advance constraint assumption.
} 
Figure 1: Timing

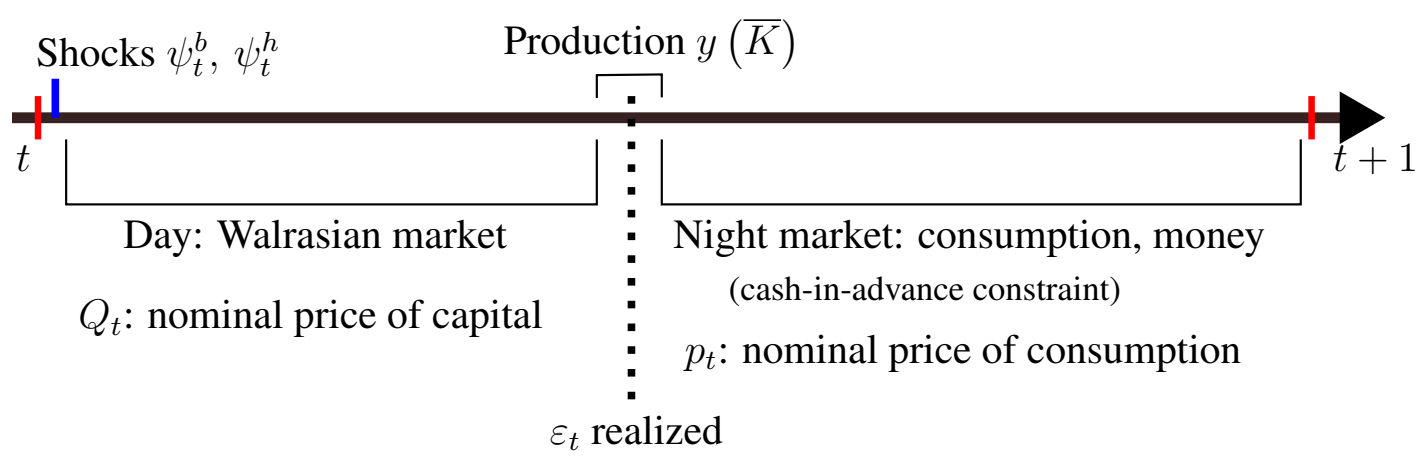

where $K_{t-1}^{i}$ is capital, $m_{t-1}^{i}$ is money, and $d_{t-1}^{i}$ are deposits whose values have been determined at $t-1$. The initial stock of capital of agent $i$ is $K_{t-1}^{i}\left(1+\psi_{t}^{i}\right)$ where $\psi_{t}^{i}$ is an idiosyncratic shock realized at time $t$ with support $\psi_{t}^{i} \in\{\underline{\psi}, 0, \bar{\psi}\}$, $-1<\underline{\psi}<0<\bar{\psi}$. The value of $\psi_{t}^{i}$ is private information of agent $i$ during the day, while it becomes common knowledge at night.

The shocks $\left\{\psi_{t}^{i}\right\}$ are idiosyncratic in the sense that the law of large numbers holds: $\int K_{t}^{i} \psi_{t}^{i} d i=0$. I also assume that the law of large numbers holds both within the banking sector and within the household sector:

$$
\int_{\mathbb{B}} K_{t-1}^{b} \psi_{t}^{b} d b=0, \quad \int_{\mathbb{H}} K_{t-1}^{h} \psi_{t}^{h} d h=0
$$

I assume that $\operatorname{Pr}\left(\psi_{t}^{i}=0\right.$ for all $\left.i \in \mathbb{H} \cup \mathbb{B}\right)=1$, and I will analyze the effects of one-time unanticipated shocks. When the one-time unanticipated shocks hit the economy, shocks take the values $\psi_{t}^{i}=\psi$ (negative shock) with probability $\alpha \in$ $(0,1)$ and $\psi_{t}^{i}=\bar{\psi}$ (positive shock) with probability $1-\alpha .{ }^{8}$

\subsection{Banking}

Deposits (day). I Impose a particular demand-deposit contract, rather than deriving it from an explicit contracting problem. In this Section, I describe the restrictions that I impose on the deposit contract. In Online Appendix B.3, I provide some

\footnotetext{
${ }^{8}$ Online Appendix B.2 provides an interpretation of the shock $\psi_{t}^{i}$ and presents an alternative formulation to define the shocks.
} 
justification for these restrictions.

Assumption 2.1. (Nominal demand-deposit contract) A deposit is redeemable for a value specified in terms of money.

Assumption 2.2. (One bank per household) Each household $h \in \mathbb{H}$ can hold deposits $D_{t}^{h}$ (at most) at one bank.

Assumption 2.1 imposes that households and banks can use only demand-deposit contracts in nominal terms. Assumption 2.2 can be justified by costs of maintaining banking relationships. Formally, the cost would be zero if household $h$ holds deposits at one bank, and infinite if household $h$ holds deposits at two or more banks. Assumption 2.2 can be relaxed, but it is crucial that households cannot hold deposits at a large number of banks.

To clarify the notation and the timing, note that household $h$ starts period $t$ with preexisting deposits $d_{t-1}^{h}$, and bank $b$ starts period $t$ with preexisting deposits $d_{t-1}^{b}$. The choice $D_{t}^{h}$ taken by household $h$ is thus a decision regarding rolling over her preexisting deposits $d_{t-1}^{h}$ (fully or partially) and/or increasing her deposits. For instance, if $D_{t}^{h}=d_{t-1}^{h}$ then the value of deposits of household $h$ stays constant. For bank $b$, the difference $D_{t}^{b}-d_{t-1}^{b}$ is the net issuance of deposits. If $D_{t}^{b}>d_{t-1}^{b}$, bank $b$ increases its deposits and thus receives new resources from households. Otherwise, bank $b$ reduces its amount of preexisting deposits and must pay back some resources to households. ${ }^{9}$

For future reference, let $\mathbb{H}(b) \subset \mathbb{H}$ be the set of depositors of bank $b \in \mathbb{B}$, and let $b(h) \in \mathbb{B}$ be the bank of household $h \in \mathbb{H}$.

Withdrawals (night). At night, households learn the realization of their own preference shock $\varepsilon_{t}^{h}$. They then decide to withdraw $w_{t}^{h}$ from their own bank subject to a sequential service constraint. They then decide to consume $c_{t}^{h}$.

${ }^{9}$ To describe precisely the interaction between banks and depositors, I must specify what happens if many preexisting deposits are not rolled over during the day and the bank does not have enough resources to repay them, i.e., there is not enough pre-existing money $m_{t-1}^{b}$ and capital $K_{t-1}^{b}\left(1+\psi_{t}^{b}\right)$. If such circumstances occur, the bank is shut down immediately and depositors get pro-rata repayments. 
Assumption 2.3. (Withdrawals) As long as bank $b(h) \in \mathbb{B}$ has money to pay withdrawals, depositor $h$ can withdraw any amount of money less or equal than the value of her deposits chosen during the day, $D_{t}^{h}$.

In the event of large withdrawals from a bank, the bank might not have enough cash to serve all households. Household $h$ can withdraw any amount $0 \leq w_{t}^{h} \leq$ $\min \left\{D_{t}^{h}, l_{t}^{h}\right\}$ where $l_{t}^{h} \in\{0,+\infty\}$ is a limit on withdrawals determined by the position in the line. If household $h$ is served when the bank is out of money, then $l_{t}^{h}=0$ and thus $w_{t}^{h}=0$. If household $h$ is served when the bank still has money, then $l_{t}^{h}=+\infty$ and $0 \leq w_{t}^{h} \leq D_{t}^{h}$.

Bank $b$ is subject to a run if the limit on withdrawals is $l_{t}^{h}=0$ for some $h \in$ $\mathbb{H}(b)$. If bank $b$ is subject to a run, the bank is liquidated at $t+1$ while the day market is open. Liquidation works as follows. All assets of the bank are sold on the market, and deposits not withdrawn at night are repaid (if the value of assets is insufficient, depositors are repaid pro-rata). ${ }^{10}$

Due to the cash-in-advance constraint, consumption expenditures $p_{t} c_{t}^{h}$ cannot exceed the sum of money $M_{t}^{h}$ chosen during the day and withdrawals $w_{t}^{h}$ chosen at night, $p_{t} c_{t}^{h} \leq M_{t}^{h}+w_{t}^{h}$.

Banks do not make any economic decisions at night. The amount of money withdrawn by depositors of bank $b$ is $w_{t}^{b}=\int_{\mathbb{H}(b)} w_{t}^{h} d h$. Withdrawals $w_{t}^{b}$ are limited by the feasibility constraint $w_{t}^{b} \leq M_{t}^{b}$ (money that is distributed at night to depositors cannot exceed the amount $M_{t}^{b}$ that bank $b$ held at the end of the day).

Return on deposits. During the day of period $t$, banks promise to pay a return $1+R_{t}^{D}$ (in $t+1$ ) on deposits that are not withdrawn that night. ${ }^{11}$

Assumption 2.4. (Return on deposits withdrawn) Banks pay no return on deposits withdrawn at night.

\footnotetext{
${ }^{10}$ The case in which the value of assets of the banks is higher then the value of deposits not withdrawn is discussed for completeness in Online Appendix A, but it is not relevant for the main results of the paper.

${ }^{11}$ The term $1+R_{t}^{D}$ is the face value of deposits, conditional on not withdrawing at night. Note that $R_{t}^{D}$ is a market price that is taken as given by both banks and households. The results are unchanged if I allow each bank to post a bank-specific return during the day.
} 
Banks might not have enough resources to pay the promised return $R_{t}^{D}$. Define $r_{t}^{b} \leq R_{t}^{D}$ to be the actual return on deposits. Note that $r_{t}^{b}$ can be lower than the promised return; if that is the case, then the quantity $1+r_{t}^{b}$ has the interpretation of recovery rate. The value of deposits at the end of the night $d_{t}^{h}$ for household $h$ is $d_{t}^{h} \equiv\left(D_{t}^{h}-w_{t}^{h}\right)\left(1+r_{t}^{b(h)}\right)$. For bank $b \in \mathbb{B}$, it is useful to define the value of deposits at the end of the night as $d_{t}^{b} \equiv\left(D_{t}^{b}-w_{t}^{b}\right)\left(1+R_{t}^{D}\right)$. That is, the value depends on the promised return $R_{t}^{D}$ rather than the actual return $r_{t}^{b}$.

\subsection{State of the economy and sunspot}

The aggregate state of the economy $\boldsymbol{X}_{t}$ at the beginning of the day is $\boldsymbol{X}_{t}=$ $\left\{\operatorname{Pr}_{t}^{B}, s_{t}\right\}$, where $\operatorname{Pr}_{t}^{B}$ is the probability distribution over the states of banks $\boldsymbol{X}_{t}^{b}$ and $s_{t}$ is a sunspot. ${ }^{12}$ The sunspot is an exogenous process that determines equilibrium selection, when multiple equilibria exist. The sunspot $s_{t}$ selects the good equilibrium with probability one, so the bad equilibrium is unanticipated.

For all agents in the model, knowledge of the aggregate state only conveys information about the overall distribution of assets and liabilities of banks. It does not clarify the assets, liabilities, and realization of $\psi_{t}^{b}$ of any particular bank $b \in \mathbb{B}$.

\section{Equilibrium}

I describe the problem of banks (Section 3.1), the problem of households (Section 3.2) and then I define the notion of equilibrium (Section 3.4). For future reference, let $R_{t}^{K}$ be the nominal return on capital:

$$
1+R_{t}^{K} \equiv \frac{Q_{t+1}+Z p_{t}}{Q_{t}}
$$

\subsection{Bank problem}

Given the vector of state variables $\boldsymbol{X}_{t}^{b}=\left\{\left(K_{t-1}^{b}, m_{t-1}^{b}, d_{t-1}^{b}\right), \psi_{t}^{b}\right\}$ and the price of capital $Q_{t}$, the balance sheet of a bank $b$ at the beginning of the day is:

\footnotetext{
${ }^{12}$ I will impose restrictions on initial conditions so that the states of banks take finitely many values.
} 


Assets
Value of capital $=K_{t-1}^{b}\left(1+\psi_{t}^{b}\right) Q_{t}$
Money $=m_{t-1}^{b}$

Value of deposits $=d_{t-1}^{b}$

Net worth $=N_{t}^{b}$

where net worth is the difference between the value of assets and the value of deposits:

$$
N_{t}^{b} \equiv K_{t-1}^{b}\left(1+\psi_{t}^{b}\right) Q_{t}+m_{t-1}^{b}-d_{t-1}^{b}
$$

The net worth $N_{t}^{b} \in \mathbb{R}$, so it can be either positive or negative. If $N_{t}^{b} \geq 0$, the bank is solvent (the value of its assets is larger than deposits $d_{t}^{b}$ ). If $N_{t}^{b}<0$, the bank is insolvent (the value of its assets is less than deposits $d_{t}^{b}$ ). Note that a bank with negative net worth can be active in equilibrium because of asymmetric information about $\psi_{t}^{b}$. Since bank $b$ takes the price $Q_{t}$ as given, the net worth $N_{t}^{b}$ summarizes the vector of state variables $\boldsymbol{X}_{t}^{b}$ for the purpose of understanding the choices of bank $b$.

Profit maximization is equivalent to maximizing $N_{t+1}^{b}$ subject to limited liability, $\max \left\{0, N_{t+1}^{b}\right\}$ (see Online Appendix A.2 for more details). Given $N_{t}^{b}$, bank $b \in \mathbb{B}$ chooses deposits $D_{t}^{b}$, money $M_{t}^{b}$, and capital $K_{t}^{b}$, taking as given the market return on deposits $R_{t}^{D}$ and withdrawals $w_{t}^{b}$ by depositors at night:

$$
\max _{D_{t}^{b}, M_{t}^{b}, K_{t}^{b}} \mathbb{E}_{\psi} \max \left\{0, N_{t+1}^{b}\right\}
$$

subject to the budget constraint (7) and the law of motion of net worth (8):

$$
\begin{gathered}
K_{t}^{b} Q_{t}+M_{t}^{b} \leq D_{t}^{b}+N_{t}^{b} \\
N_{t+1}^{b}=K_{t}^{b}\left(1+\psi_{t+1}^{b}\right) Q_{t+1}+m_{t}^{b}-d_{t}^{b}
\end{gathered}
$$

where $m_{t}^{b}$ and $d_{t}^{b}$ are money and deposits at the end of the night of time $t$ :

$$
m_{t}^{b} \equiv\left[\left(M_{t}^{b}-w_{t}^{b}\right)+y\left(K_{t}^{b}\right) p_{t}\right], \quad d_{t}^{b} \equiv\left(D_{t}^{b}-w_{t}^{b}\right)\left(1+R_{t}^{D}\right)
$$

The expectation $\mathbb{E}_{\psi}$ is taken with respect to the shock to capital $\psi_{t+1}^{b}$. Banks must 
also satisfy non-negativity constraints $D_{t}^{b} \geq 0, M_{t}^{b} \geq 0$, and $K_{t}^{b} \geq 0$. The solution to the problem of banks is summarized by Proposition 3.1 when the non-negativity constraints are not binding, which is relevant for most of the paper; the proof is provided in Online Appendix C. Online Appendix D presents and discusses a situation in which the non-negativity constraints are binding.

Proposition 3.1. Given $N_{t}^{b}$ and prices $Q_{t}, R_{t}^{K}, R_{t}^{D} \geq 0$, the optimal choice of bank $b$ is:

1. deposits:

$$
D_{t}^{b}= \begin{cases}0 & \text { if } R_{t}^{D}>R_{t}^{K} \\ \text { any amount } \geq 0 & \text { if } R_{t}^{D}=R_{t}^{K} \\ +\infty & \text { if } R_{t}^{D}<R_{t}^{K}\end{cases}
$$

2. money holding $M_{t}^{b}=\kappa D_{t}^{b}$;

3. capital holding $K_{t}^{b}=\frac{N_{t}^{b}+D_{t}^{b}-M_{t}^{b}}{Q_{t}}$; provided that the non-negativity constraints $M_{t}^{b} \geq 0$ and $K_{t}^{b} \geq 0$ are not binding.

To understand the result, consider first a bank that starts with zero net worth, $N_{t}^{b}=0$. The law of large numbers about the preference shocks $\varepsilon_{t}^{h}$ implies that a fraction $\kappa$ of depositors withdraw at night to finance consumption expenditures. Thus banks keep an amount of money $M_{t}^{b}=\kappa D_{t}^{b}$ that is just enough to finance such withdrawals. The remaining resources $D_{t}^{b}-M_{t}^{b}=(1-\kappa) D_{t}^{b}$ are invested in capital, yielding a net return $(1-\kappa) D_{t}^{b} R_{t}^{K}$ in $t+1$. As the bank will have to pay the return $(1-\kappa) D_{t}^{b} R_{t}^{D}$ on deposits not withdrawn, the profit of the bank is $(1-\kappa) D_{t}^{b}\left(R_{t}^{K}-R_{t}^{D}\right)$. Thus, the bank chooses $D_{t}^{b}=0$ if $R_{t}^{K}<R_{t}^{D}$ (otherwise it would make negative profit), $D_{t}^{b}=+\infty$ if $R_{t}^{K}>R_{t}^{D}$ (because it can make strictly positive profits on every dollar of deposit), and it is indifferent among any $D_{t}^{b}$ if $R_{t}^{K}=R_{t}^{D}$ (making zero profits).

If a bank has a positive net worth, $N_{t}^{b}>0$, a similar analysis applies. The bank invests a fraction $\kappa$ of deposits in money and a fraction $1-\kappa$ in capital. The whole net worth $N_{t}^{b}$ is invested in capital to maximize the value of net worth tomorrow.

For a bank with negative net worth, $N_{t}^{b}<0$, I explain here only the relevant equilibrium case $R_{t}^{K}=R_{t}^{D}$. A bank $b$ with negative net worth does not earn profits 
on deposits if $R_{t}^{K}=R_{t}^{D}$. Therefore, its net worth at $t+1$ remains negative. ${ }^{13}$ Consequently, the bank is indifferent between its choices (because its payoff will always be zero due to limited liability) and taking the same choices as a solvent bank is (weakly) optimal.

\subsubsection{Actual return on deposits}

The actual return on deposits $r_{t}^{b}$ is defined as:

$$
r_{t}^{b} \equiv \min \left\{R_{t}^{D}, \widehat{r}_{t}^{b}\right\}
$$

The variable $\widehat{r}_{t}^{b}$ is the return that can be paid to deposits not withdrawn using proceeds from selling output $Z K_{t}^{b} p_{t}$ and the value of capital $K_{t}^{b} Q_{t+1}$ that a bank has at the beginning of $t+1$. Thus, $\widehat{r}_{t}^{b}$ solves:

$$
\mathbb{E}_{\psi}\left\{K_{t}^{b}\left(1+\psi_{t+1}^{b}\right) Q_{t+1}\right\}+Z K_{t}^{b} p_{t}=\left(D_{t}^{b}-w_{t}^{b}\right)\left(1+\widehat{r}_{t}^{b}\right)
$$

or, using $\psi_{t+1}^{b}=0$ with probability one and rearranging:

$$
1+\widehat{r}_{t}^{b}=\frac{K_{t}^{b}\left(Q_{t+1}+Z p_{t}\right)}{D_{t}^{b}-w_{t}^{b}}
$$

\subsubsection{Fraction of depositors served during a run}

If all depositors of bank $b$ attempt to withdraw money at night, only a fraction $f_{t}^{b}$ of depositors will be served. The fraction of depositors served is:

$$
f_{t}^{b}=\frac{M_{t}^{b}}{D_{t}^{b}}
$$

From the viewpoint of household $h$ that has deposits at bank $b(h)$, if all depositors of bank $b$ attempt to withdraw their deposits, then household $h$ is able to withdraw with probability $f_{t}^{b(h)}$.

\footnotetext{
${ }^{13}$ Note also that the bank cannot invest $100 \%$ of its deposits in money because $M_{t}^{b}<D_{t}^{b}+N_{t}^{b}$ using the budget constraint (7) and $N_{t}^{b}<0$.
} 


\subsection{Household problem}

Given the vector of state variables $\boldsymbol{X}_{t}^{h}=\left\{\left(K_{t-1}^{h}, m_{t-1}^{h}, d_{t-1}^{h}\right), \psi_{t}^{h}\right\}$ of household $h$ and the price of capital $Q_{t}$, the nominal wealth $A_{t}^{h}$ of household $h$ is:

$$
A_{t}^{h} \equiv K_{t-1}^{h}\left(1+\psi_{t}^{h}\right) Q_{t}+m_{t-1}^{h}+d_{t-1}^{h} .
$$

Household $h \in \mathbb{H}$ is assigned a bank $b(h) \in \mathbb{B}$. Let $n_{t}^{h}=\left\{\varepsilon_{t}^{h}, r_{t}^{b(h)}, l_{t}^{h}\right\} \in \mathcal{N}$ be the vector of variables whose value is learnt by household $h$ at night, where $\mathcal{N}=\{n=\{\varepsilon, r, l\} \mid \varepsilon \in\{\bar{\varepsilon}, \varepsilon\}, r \in \mathbb{R}, l \in\{0,+\infty\}\}$. First, household $h$ forms beliefs $\operatorname{Pr}_{t}^{h}\left(r_{t}^{b(h)}=r, l_{t}^{h}=l\right)$ that, combined with the exogenous process for $\varepsilon_{t}^{h}$ described in (1), imply a probability distribution over $n \in \mathcal{N}$. Second, during the day, household $h$ chooses money $M_{t}^{h}$, deposits $D_{t}^{h}$, and capital $K_{t}^{h}$. Third, at night, household $h$ observes $n_{t}^{h}$ and chooses withdrawals $w^{h}\left(n_{t}^{h}\right)$ and consumption $c^{h}\left(n_{t}^{h}\right)$.

Let $V_{t}\left(A_{t}^{h}\right)$ be the value of holding nominal wealth $A_{t}^{h}$. The Bellman equation is:

$$
V_{t}\left(A_{t}^{h}\right)=\max _{M_{t}^{h}, D_{t}^{h}, K_{t}^{h}} \mathbb{E}_{n}\left\{\max _{w^{h}\left(n_{t}^{h}\right), c^{h}\left(n_{t}^{h}\right)}\left[\varepsilon_{t}^{h} \log c^{h}\left(n_{t}^{h}\right)+\beta \mathbb{E}_{\psi} V_{t+1}\left(A_{t+1}^{h}\left(n_{t}^{h}, \psi_{t+1}^{h}\right)\right)\right]\right\}
$$

subject to the budget constraint (15), the limit on withdrawals (16), the cash-inadvance constraint (17), and a non-negativity constraint on money $M_{t}^{h} \geq 0$, deposits $D_{t}^{h} \geq 0$, and capital $K_{t}^{h} \geq 0$ :

$$
\begin{gathered}
M_{t}^{h}+D_{t}^{h}+Q_{t} K_{t}^{h} \leq A_{t}^{h} \\
0 \leq w^{h}\left(n_{t}^{h}\right) \leq \min \left\{D_{t}^{h}, l_{t}^{h}\right\} \\
p_{t} c^{h}\left(n_{t}^{h}\right) \leq M_{t}^{h}+w^{h}\left(n_{t}^{h}\right)
\end{gathered}
$$

where the value of wealth $A_{t+1}^{h}\left(n_{t}^{h}, \psi_{t+1}^{h}\right)$ is:

$$
A_{t+1}^{h}\left(n_{t}^{h}, \psi_{t+1}^{h}\right)=\left[K_{t}^{h}\left(1+\psi_{t+1}^{h}\right)\right] Q_{t+1}+d^{h}\left(n_{t}\right)+m^{h}\left(n_{t}^{h}\right)
$$


and:

$$
\begin{gathered}
d^{h}\left(n_{t}^{h}\right) \equiv\left[D_{t}^{h}-w^{h}\left(n_{t}^{h}\right)\right]\left(1+r_{t}^{b(h)}\right) \\
m^{h}\left(n_{t}^{h}\right) \equiv\left[M_{t}^{h}+w^{h}\left(n_{t}^{h}\right)-p_{t} c^{h}\left(n_{t}^{h}\right)\right]+p_{t} Z K_{t}^{h} .
\end{gathered}
$$

The term $d^{h}\left(n_{t}^{h}\right)$ represents deposits not withdrawn $D_{t}^{h}-w^{h}\left(n_{t}^{h}\right)$, plus the actual return $r_{t}^{b(h)}$ paid by bank $b(h)$. The term $m^{h}\left(n_{t}^{h}\right)$ is money at the end of the night, which is the sum of the unspent money at night (i.e., money held during the day $M_{t}^{h}$ plus withdrawals $w^{h}\left(n_{t}^{h}\right)$ minus consumption expenditure $\left.c^{h}\left(n_{t}^{h}\right) p_{t}\right)$ plus proceeds from selling output $Z K_{t}^{h}$ at night at price $p_{t}$. The expectation $\mathbb{E}_{n}$ is taken with respect to the beliefs over $n \in \mathcal{N}$, and the expectation $\mathbb{E}_{\psi}$ is taken with respect to the shock to capital $\psi_{t+1}^{h}$.

If $R_{t}^{D}=R_{t}^{K}$ and household $h$ has belief $r_{t}^{b(h)}=R_{t}^{D}$ with probability one (which is the case in the good equilibrium), households are indifferent between investing directly a fraction of their wealth in capital, or depositing more and letting banks buy capital on their behalf. To simplify the derivation, I impose Assumption 3.2.

Assumption 3.2. If household $h \in \mathbb{H}$ is indifferent among several choices of $D_{t}^{h}$, the household selects the smallest $D_{t}^{h}$ that maximizes her utility.

Assumption 3.2 implies that households use banks only to insure against liquidity risk, and invest directly in capital all the wealth they want to carry to $t+1$. The assumption is irrelevant for the bad equilibrium (because the optimal $D_{t}^{h}$ is unique), and it does not affect prices in the good equilibrium.

Proposition 3.3 states the solution to problem (14), focusing on the relevant case $R_{t}^{D}=R_{t}^{K}$. The proof is provided in Online Appendix C.

Proposition 3.3. Given beliefs $\operatorname{Pr}_{t}^{h}(\cdot)$ and prices $Q_{t}, R_{t}^{K}$, and $R_{t}^{D}=R_{t}^{K}$, household h chooses:

- (day) $M_{t}^{h}=\eta_{t}^{M} A_{t}^{h}, D_{t}^{h}=\eta_{t}^{D} A_{t}^{h}, Q_{t} K_{t}^{h}=\eta_{t}^{K} A_{t}^{h}$, where $\eta_{t}^{M}, \eta_{t}^{D}, \eta_{t}^{K} \in[0,1]$ are independent of $A_{t}^{h}$ and $\eta_{t}^{M}+\eta_{t}^{D}+\eta_{t}^{K}=1$;

- (night) withdrawals and consumption: 


$$
\begin{aligned}
& w_{t}^{h}=w^{h}\left(n_{t}^{h}\right)=\left\{\begin{array}{cll}
D_{t}^{h} & \text { if } \varepsilon_{t}^{h}=\bar{\varepsilon}, \quad r_{t}^{b(h)} \in \mathbb{R}, & \text { and } l_{t}^{h}=+\infty \\
0 & \text { if } \varepsilon_{t}^{h}=\bar{\varepsilon}, \quad r_{t}^{b(h)} \in \mathbb{R}, & \text { and } l_{t}^{h}=0 \\
D_{t}^{h} & \text { if } \varepsilon_{t}^{h}=0, \quad r_{t}^{b(h)}<0, & \text { and } l_{t}^{h}=+\infty \\
0 & \text { if } \varepsilon_{t}^{h}=0, \quad r_{t}^{b(h)}<0, & \text { and } l_{t}^{h}=0 \\
0 & \text { if } \varepsilon_{t}^{h}=0, \quad r_{t}^{b(h)} \geq 0, & \text { and } l_{t}^{h} \in\{0,+\infty\},
\end{array}\right. \\
& c_{t}^{h}=c^{h}\left(n_{t}^{h}\right)= \begin{cases}0 & \text { if } \varepsilon_{t}^{h}=0 \\
\frac{M_{t}^{h}+w^{h}\left(n_{t}^{h}\right)}{p_{t}} & \text { if } \varepsilon_{t}^{h}=\bar{\varepsilon} .\end{cases}
\end{aligned}
$$

Since the felicity from consumption is log, I guess and verify that household choices during the day are proportional to initial wealth $A_{t}^{h}$. At night, an impatient household $\left(\varepsilon_{t}^{h}=\bar{\varepsilon}\right)$ withdraws deposits if unconstrained $\left(l_{t}^{h}=+\infty\right)$ and uses money $M_{t}^{h}=\eta_{t}^{M} A_{t}^{h}$ and withdrawals $w_{t}^{h}$ to finance her consumption expenditures. If the household is patient $\left(\varepsilon_{t}^{h}=0\right)$, her choice of consumption is zero, but she is nonetheless willing to withdraw if the actual return on deposits is negative $\left(r_{t}^{b(h)}<0\right)$. In this crucial case, the nominal return on money is zero, thus higher than the nominal return on deposits not withdrawn. The household runs on the bank and withdraws all the available deposits $D_{t}^{h}$ if the bank still has money while household $h$ is served $\left(l_{t}^{h}=+\infty\right)$. If instead the bank has no money $\left(l_{t}^{h}=0\right)$, the household is stuck with zero withdrawals and receives a negative return on deposits.

Since $M_{t}^{h}, D_{t}^{h}$, and $K_{t}^{h}$ are proportional to initial wealth $A_{t}^{h}$, Corollary 3.4 holds.

Corollary 3.4. The choices $\left\{M_{t}^{h}, D_{t}^{h}, K_{t}^{h}\right\}_{h \in \mathbb{H}}$ of the household sector can be described by a representative household with initial wealth $\bar{A}_{t} \equiv \int_{\mathbb{H}} A_{t}^{h} d h$.

Consequently, the shocks $\psi_{t}^{h}$ to the capital owned by the household sector are irrelevant from an equilibrium perspective, because they simply modify the distribution of wealth, but they do not influence the total value of wealth $\bar{A}_{t}$. It is, however, crucial that the idiosyncratic shocks to capital hit the balance sheet of banks, creating heterogeneity in the banking sector. 


\subsection{Market clearing conditions}

The market clearing conditions are as follows.

$$
\begin{aligned}
\text { Capital market, day: } & \int_{\mathbb{B}} K_{t}^{b} d b+\int_{\mathbb{H}} K_{t}^{h} d h=\bar{K} . \\
\text { Money market, day: } & \int_{\mathbb{B}} M_{t}^{b} d b+\int_{\mathbb{H}} M_{t}^{h} d h=\bar{M} . \\
\text { Deposits, day: } & \int_{\mathbb{B}} D_{t}^{b} d b=\int_{\mathbb{H}} D_{t}^{h} d h . \\
\text { Goods market, night: } & \int_{\mathbb{H}} c_{t}^{h} d h=Z \bar{K} .
\end{aligned}
$$

\subsection{Equilibrium definition}

Given the state of the economy $\boldsymbol{X}_{t}$ (described in Section 2.4), the distribution over banks' state $\operatorname{Pr}_{t}^{B}$ and the price of capital $Q_{t}$ imply the distribution $\operatorname{Pr}_{t}^{N}$ over net worth $\left\{N_{t}^{b}\right\}_{b \in \mathbb{B}}$ defined by:

$$
\operatorname{Pr}_{t}^{N}\left(N_{t}^{b}=N ; Q_{t}\right)=\sum_{\left\{\boldsymbol{X}_{t}^{b} \mid K_{t-1}^{b}\left(1+\psi_{t}^{b}\right) Q_{t}+m_{t-1}^{b}-d_{t-1}^{b}=N\right\}} \operatorname{Pr}_{t}^{B}\left(\boldsymbol{X}_{t}^{b}\right)
$$

Although the probability $\operatorname{Pr}_{t}^{B}$ over $\boldsymbol{X}_{t}^{b}$ is given by the state of the economy, the probability $\operatorname{Pr}_{t}^{N}$ is an endogenous object because it depends on the price of capital $Q_{t}$. For a given $\operatorname{Pr}_{t}^{B}$, the price of capital influences the solvency of banks in the economy. The role of $Q_{t}$ in the determination of net worth is central to the existence of multiple equilibria.

I claim that, given prices, a link between $\operatorname{Pr}_{t}^{N}$ and the distribution over $\left\{r_{t}^{b(h)}, l_{t}^{h}\right\}_{h \in \mathbb{H}}$ can be established. The net worth $N_{t}^{b}$ of bank $b \in \mathbb{B}$ determines the choices of money $M_{t}^{b}$, deposits $D_{t}^{b}$, and capital $K_{t}^{b}$ (see Proposition 3.1), which in turn determine $r_{t}^{b}$ and $f_{t}^{b}$ (see equations (10) and (12)). ${ }^{14}$ I denote:

$$
\operatorname{Pr}_{t}^{(r, l)}\left(r_{t}^{b(h)}=r, l_{t}^{h}=l\right), r \in \mathbb{R} \text { and } l \in\{0,+\infty\}
$$

\footnotetext{
${ }^{14}$ Recall from Section 3.1.2 that an household is served $\left(l_{t}^{h}=+\infty\right)$ with probability $f_{t}^{b(h)}$ if all depositors run on bank $b$.
} 
to be the probability distribution over the actual return on deposits $r_{t}^{b(h)}$ and the limit on withdrawal $l_{t}^{h}$ for household $h \in \mathbb{H}$. In equilibrium, I require households' beliefs $\operatorname{Pr}_{t}^{h}$ to be rational, in the sense that they must be equal to the realized probability distribution (25).

Note that, since I force $R_{t}^{D}$ to be equalized across all banks, I impose a pooling equilibrium in the banking market, similar to Akerlof (1970). The results are unchanged if I allow each bank $b$ to post a bank-specific promised return on deposits. In this case, the equilibrium that arises is still a pooling one because bad banks want to imitate good banks to survive as long as possible.

The next definition formalizes the equilibrium concept.

Definition 3.5. Given the initial state of the economy $\boldsymbol{X}_{t}$, an equilibrium is a collection of:

- prices $Q_{t}$ and $p_{t}$ and return on capital $R_{t}^{K}$ and on deposits $R_{t}^{D}$;

- household beliefs $\operatorname{Pr}_{t}^{h}(\cdot)$, for all $h \in \mathbb{H}$;

- household choices $\left\{M_{t}^{h}, D_{t}^{h}, K_{t}^{h},\left\{w^{h}\left(n_{t}^{h}\right), c^{h}\left(n_{t}^{h}\right)\right\}_{n_{t}^{h} \in \mathcal{N}}\right\}$ for all $h \in \mathbb{H}$;

- bank choices $\left\{D_{t}^{b}, M_{t}^{b}, K_{t}^{b}\right\}$ for all $b \in \mathbb{B}$;

- limits on withdrawals $l_{t}^{h} \in\{0,+\infty\}$ for all $h \in \mathbb{H}$;

- actual return on deposits $r_{t}^{b}$ and fraction of depositors served in the event of a run $f_{t}^{b}$, for all $b \in \mathbb{B}$;

such that:

- (banks: optimality, returns, and limits on withdrawals) banks solve problem (6); $r_{t}^{b}$ and $f_{t}^{b}$ satisfy, respectively, equations (10) and (12) and: ${ }^{15}$

$$
l_{t}^{h}=0 \text { for some } h \in \mathbb{H}(b) \Rightarrow \int_{\mathbb{H}(b)} w^{h}\left(n_{t}^{h} \mid l_{t}^{h}=+\infty\right) d h>M_{t}^{b}
$$

- (households' optimality) households solve problem (14) and Assumption 3.2 holds;

- (rational expectations) households' beliefs are rational, i.e., for all $h \in \mathbb{H}$

$$
\operatorname{Pr}_{t}^{h}\left(r_{t}^{b(h)}=r, l_{t}^{h}=l\right)=\operatorname{Pr}_{t}^{(r, l)}\left(r_{t}^{b(h)}=r, l_{t}^{h}=l\right), \quad r \in \mathbb{R} \text { and } l \in\{0,+\infty\}
$$

\footnotetext{
${ }^{15}$ This condition says that if a household faces a limit on withdrawals $l_{t}^{h}=0$, then the unconstrained amount of withdrawals $\int_{\mathbb{H}(b)} w^{h}\left(n_{t}^{h} \mid l_{t}^{h}=+\infty\right) d h$ is not feasible).
} 
- (market clearing) the market clearing conditions hold.

I focus on symmetric equilibria in which banks with the same net worth make the same choices, in particular for deposits $\left(N_{t}^{b}=N_{t}^{b^{\prime}} \Rightarrow D_{t}^{b}=D_{t}^{b^{\prime}}\right.$ for $\left.b, b^{\prime} \in \mathbb{B}\right)$.

\section{Results}

Section 4.1 first describes the steady-state with no shocks to capital. Then, starting from the economy in steady-state, I consider the effects of one-time unanticipated idiosyncratic shocks to capital at time $t, \psi_{t}^{i} \in\{\underline{\psi}, \bar{\psi}\}$ for all $i \in \mathbb{H} \cup \mathbb{B}$. At time $t$, multiple equilibria can arise: a good equilibrium where prices and aggregate quantities are the same as in the steady-state; and up to three bad equilibria described in Section 4.2. If the economy experiences a crisis at time $t$ (bad equilibrium), the crisis lasts one period, and the economy is in steady-state from $t+1$ onward.

I impose two restrictions on initial conditions. All banks are alike at the beginning of the day, and their holdings of capital and money are enough to guarantee that banks hit by the negative shock $\psi$ are solvent in the good equilibrium.

Assumption 4.1. At time $t$, the vector of state variables $\boldsymbol{X}_{t}^{b}$ is the same for all banks, i.e., for all $b, b^{\prime} \in \mathbb{B}, K_{t-1}^{b}=K_{t-1}^{b^{\prime}}, m_{t-1}^{b}=m_{t-1}^{b^{\prime}}, d_{t-1}^{b}=d_{t-1}^{b^{\prime}}$, and they satisfy:

$$
K_{t-1}^{b}(1+\underline{\psi})\left[\frac{\beta}{1-\beta}+\left(\frac{1}{\kappa}-1\right)\right] \frac{\bar{M}}{\bar{K}}+m_{t-1}^{b}-d_{t-1}^{b} \geq 0 .
$$

\subsection{Steady-state and good equilibrium}

Steady-state. ${ }^{16} \quad$ In steady-state, prices are constant $\left(Q_{t}=Q^{*}, p_{t}=p^{*}\right.$ and $R_{t}^{K}=$ $R^{*}$ ). Due to Assumption 4.1, all banks are identical and solvent. The return on deposits is equal to the return on capital $\left(R_{t}^{D}=R_{t}^{K}=R^{*}\right)$; all banks pay the promised return on deposits that are not withdrawn $\left(r_{t}^{b}=R_{t}^{D}=R^{*}\right)$; and there are no runs $\left(l_{t}^{h}=+\infty\right.$ for all $\left.h\right)$. Therefore, banks pool the liquidity risk of households, insuring them against preference shocks. The representative household holds deposits

\footnotetext{
${ }^{16}$ The existence of a well-defined steady-state requires an extension described in Online Appendix A.
} 
$D^{*}$ and no money $\left(M_{t}^{h}=0\right)$ because the well-functioning banking system offsets the precautionary demand for money. Withdrawals at night are used to finance consumption expenditure. Online Appendix A.4 presents the complete characterization of $Q^{*}, p^{*}, R^{*}$, and $D^{*}$ in closed form, as functions of the parameters.

Good equilibrium. If idiosyncratic shocks to capital $\psi_{t}^{i} \in\{\underline{\psi}, \bar{\psi}\}$ hit the economy, equation (26) guarantees that a good equilibrium exists. The idiosyncratic shocks imply a redistribution of capital within the banking sector and within the household sector, but prices and aggregate quantities in the good equilibrium are the same as in the steady-state. Intuitively, since the shocks are idiosyncratic, they have no effects on aggregate variables, because all banks remain solvent (due to Assumption 4.1). The characterization of the good equilibrium is provided in Online Appendix A.4.

\subsection{Bad equilibria}

When unanticipated shocks to capital $\underline{\psi}$ and $\bar{\psi}$ hit the economy, the good equilibrium is not the unique one, for a large subset of the parameter space. There can be up to three bad equilibria, depending on parameters.

In one of the bad equilibria, all banks are insolvent $\left(N_{t}^{b}<0\right.$ for all $\left.b\right)$, and the economy experiences a "bankless crisis". No bank is active at time $t$, so households hold money to self-insure against the preference shocks. As all banks are insolvent, asymmetric information is irrelevant in this equilibrium. ${ }^{17}$ In $t+1$, new banks are active and the economy reverts to normal. The bankless crisis cannot be extended to result in a multi-period crisis. This bad equilibrium is discussed in Online Appendix D.

Henceforth, I focus on the other two bad equilibria, in which only a fraction of banks in the economy are subject to runs and asymmetric information is crucial. These bad equilibria can be extended to result in multi-period crises. Some discussion about multi-period crises is provided in Online Appendix B.4, but the actual

\footnotetext{
${ }^{17}$ In addition, the existence of the bankless crisis equilibrium does not hinge on the shocks $\psi$ and $\bar{\psi}$ hitting the economy. In fact, if all banks are alike and have "sufficiently low" net worth, the bad bankless equilibrium exists; see Online Appendix D.
} 
analysis is left for future research.

The channel that gives rise to bad equilibria. Since all banks are alike in $t-1$, and the shock to capital can take only two values, $\psi_{t}^{b} \in\{\underline{\psi}, \bar{\psi}\}$, in equilibrium there are two groups of banks. I will use $N_{t}(\underline{\psi})$ and $r_{t}(\underline{\psi})$ to denote the net worth and the actual return on deposits of bank $b$ hit by shock $\psi_{t}^{b}=\underline{\psi}$, and similarly $N_{t}(\bar{\psi})$ and $r_{t}(\bar{\psi})$ for a bank hit by $\bar{\psi}$.

A bad equilibrium at time $t$ is characterized by four features.

1. The price level is $p_{t}<p^{*}$, and the nominal price of capital is $Q_{t}<Q^{*}$. The economy experiences deflation and a drop in (nominal) asset prices.

2. Banks hit by the bad idiosyncratic shock $\underline{\psi}<0$ are insolvent, $N_{t}(\underline{\psi})<0$. Banks hit by $\bar{\psi}$ are solvent, $N_{t}(\bar{\psi})>0$.

3. Insolvent banks pay a negative actual return on deposits, $r_{t}(\underline{\psi})<0<R_{t}^{D}$, and are subject to runs at night. Solvent banks pay the promised return $R_{t}^{D}>$ 0 and are not subject to runs.

4. The representative household holds deposits $D_{t}^{h}<D^{*}$ and money $M_{t}^{h}>0$ (flight to liquidity).

The insolvency of banks hit by $\underline{\psi}$ (Item 2 ) is a direct consequence of the drop in $Q_{t}$ (Item 1). Recall that deposits are expressed in terms of money, so the nominal value of the liabilities of banks is not affected by prices. Insolvent banks pay the actual return on deposits $r_{t}(\underline{\psi})<R_{t}^{D}$ (Item 3 ) because they are insolvent and thus do not have enough resources. Such banks are subject to runs because the actual return on deposits is negative, $r_{t}(\underline{\psi})<0$, while the return from withdrawing and holding money is zero. Therefore, running is the optimal choice of depositors. The flight to liquidity (Item 4) is a result of fear of runs (Item 3). Anticipating runs, households hold more money and fewer deposits at banks, in order to (partially) self-insure against liquidity needs.

The scenario described in Items 1 - 4 is an equilibrium because there is a feedback from the flight to liquidity (Item 4) to the drop of prices (Item 1). With the flight to money by all households, some money is held by households whose realized preference shock is $\varepsilon_{t}^{h}=0$. Such money is unspent and stored under the mattresses, so less money is used for transactions in the economy. Multiplying both 
sides of the goods market clearing condition, equation (24), by $p_{t}$ :

$$
\underbrace{p_{t} \int_{\mathbb{H}} c_{t}^{h} d h}_{\text {consumption expenditure }}=p_{t} Z \bar{K} .
$$

In the good equilibrium, the left-hand side is equal to $\bar{M}$ because all the money is spent, so $p_{t}=p^{*} \equiv \bar{M} /(Z \bar{K})$. In the bad equilibrium, the left-hand side is smaller than $\bar{M}$ because some money in the economy is unspent; therefore $p_{t}<p^{*}$. Finally, the real price of capital $Q_{t} / p_{t}$ must be constant because the bad equilibrium does not influence the productivity of capital. Thus, a drop in $p_{t}$ is associated with a drop in $Q_{t} .^{18}$

Welfare. There is a welfare loss in the bad equilibria due to consumption misallocation across households. Consider households with the same initial wealth. Optimality requires the same level of consumption for these households. Some households are last in line during a run $\left(l_{t}^{h}=0\right)$, however, and thus their consumption expenditure is limited by the inability to withdraw money from their own banks. Other households are first in line during runs or face no runs on their own bank $\left(l_{t}^{h}=+\infty\right)$, so they can withdraw money from their own banks and their consumption expenditure is higher. ${ }^{19}$

Solution method. I cannot solve for the bad equilibria in closed form, so I compute them numerically using the full non-linear model. I conjecture that, at night, households run on banks hit by the shock $\underline{\psi}$. Under this conjecture, I solve for a "candidate bad equilibrium" by solving the system of non-linear equations described in Online Appendix E, using an approach based on the numerical computa-

\footnotetext{
${ }^{18}$ The real price of capital is almost constant (but not exactly constant) due to a small wealth effect. In a version of the model with preferences that eliminate wealth effects (such as quasi-linear preferences), the real price of capital is exactly constant.

${ }^{19}$ There is an additional welfare difference between good and bad equilibria, related to the distribution of wealth across households. This effect contributes to increasing welfare in the bad equilibria. In a version of the model with features that rules out wealth effects, such as quasi-linear preferences, consumption misallocation remains the only source of welfare difference, and thus welfare is always lower in the bad equilibrium.
} 
tion of Gröbner bases. ${ }^{20}$ The "candidate bad equilibrium" is an equilibrium if the initial conjecture $r_{t}(\underline{\psi})$ is verified, so that running is indeed optimal for households.

\subsection{Numerical example}

Figure 2 and Table 1 show the results of a numerical simulated example of the model. I focus on two parameterizations that differ in the value of $\kappa$ (i.e., the probability that household $h$ is hit by the preference shock $\bar{\varepsilon}>0$ ), $\kappa=0.5$ and $\kappa=0.85$. I set $\alpha=0.1$; therefore $10 \%$ of the banks are hit by $\psi$. See Table 2 in Online Appendix $\mathrm{E}$ for the values of the other parameters.

For $\kappa=0.5$, the actual return on deposits of insolvent banks in the bad equilibrium is $r_{t}(\underline{\psi})=-0.14<0$, and the other key endogenous variables are plotted in Figure 2. The economy is in steady-state in $t=0$, experiences a crisis in $t=1$, and then reverts to normal in $t=2$. The top panel plots the prices $Q_{t}, p_{t}$, and the nominal return on capital $R_{t}^{K}$. The middle panel plots the evolution of capital held by banks (left panel) and households (right panel). During the crisis, banks have fewer resources because of the flight away from deposits. Therefore banks reduce holdings of capital with respect to pre-crisis level. Since the supply of capital is fixed, households must increase their holdings of capital in equilibrium. Interpreting the banking sector in the model as the shadow banking system in the US, and assuming that commercial banks are part of the household sector in the model, the result concerning capital holdings is consistent with the data analyzed by He et al. $(2010) .^{21}$

The bottom left panel of Figure 2 plots some key variables in the money market: money held by households during the day, deposits, and a monetary aggregate denoted M1. M1 is defined as the sum of deposits and money held by households, in line with the standard definition of such a monetary aggregate.

The bad equilibrium is associated with a flight to liquidity. Households hold fewer deposits and more money in comparison to $t=0$. As a result, the drop

\footnotetext{
${ }^{20}$ See Kubler and Schmedders (2010) for an introduction to Gröbner bases applied to the computation of equilibria in economic models.

${ }^{21} \mathrm{He}$ et al. (2010) find that, during the recent US financial crisis, securitized assets shifted from sectors dependent on repo financing to commercial banks.
} 
Table 1: Equilibria comparison, $\kappa=0.85$

\begin{tabular}{llccc}
\hline Variable & & $\begin{array}{c}\text { Good } \\
\text { Equilibrium }\end{array}$ & $\begin{array}{c}\text { Mild } \\
\text { Crisis }\end{array}$ & $\begin{array}{c}\text { Deep } \\
\text { Crisis }\end{array}$ \\
\hline Price level & $p_{t}$ & 3 & 2.79 & 2.59 \\
Price of capital & $Q_{t}$ & 80 & 73 & 70.6 \\
Money, households & $\int_{\mathbb{H}} M_{t}^{h} d h$ & 0 & 0.61 & 0.88 \\
Deposits & $\int_{\mathbb{H}} D_{t}^{h} d h$ & 1.17 & 0.46 & 0.13 \\
M1 & $\int_{\mathbb{B}} D_{t}^{b} d b+\int_{\mathbb{H}} M_{t}^{h} d h$ & 1.17 & 1.07 & 1.01 \\
Return on capital & $R_{t}^{K}$ & 0.0125 & 0.11 & 0.14 \\
Return deposits, $b$ insolvent & $r_{t}^{b}$ s.t. $N_{t}^{b}<0$ & (n.a.) & -0.13 & -0.99 \\
\hline
\end{tabular}

in M1 with constant money supply $\bar{M}$ implies a drop in the money multiplier or, equivalently, a drop in velocity in the equation of exchange $\bar{M} \cdot$ velocity $=p_{t} y(\bar{K})$, which is consistent with empirical evidence about the Great Depression and the 2008-2009 US financial crisis. ${ }^{22}$

The model qualitatively replicates some key facts of the money market during the Great Depression, plotted in the bottom right panel of Figure 2 (data are based on Friedman and Schwartz, 1970). During the Great Depression, the US economy experienced a drop in the total stock of money (top line) similar to the drop in M1, a drop in total deposits (second line from the top), and an increase in currency held by the public (bottom line).

Table 1 shows the result for $\kappa=0.85$. Under this parameterization, there exist two bad equilibria that I label "mild crisis" and "deep crisis." The two bad equilibria are qualitatively identical, but in the deep crisis equilibrium, in comparison with the mild crisis, the drop in prices is more pronounced, the flight to liquidity and the drop in M1 are greater, and the return on deposits of insolvent banks is lower. The force that gives rise to multiple bad equilibria is analyzed in the next Section. 
Figure 2: Bad equilibrium and comparison with the Great Depression
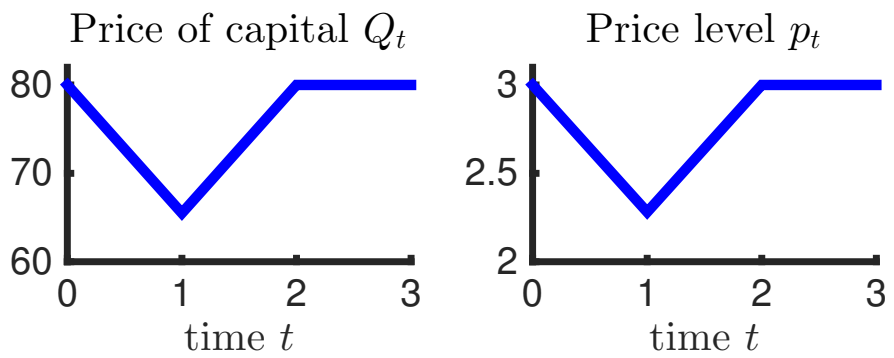

Return on capital $R_{t}^{K}$
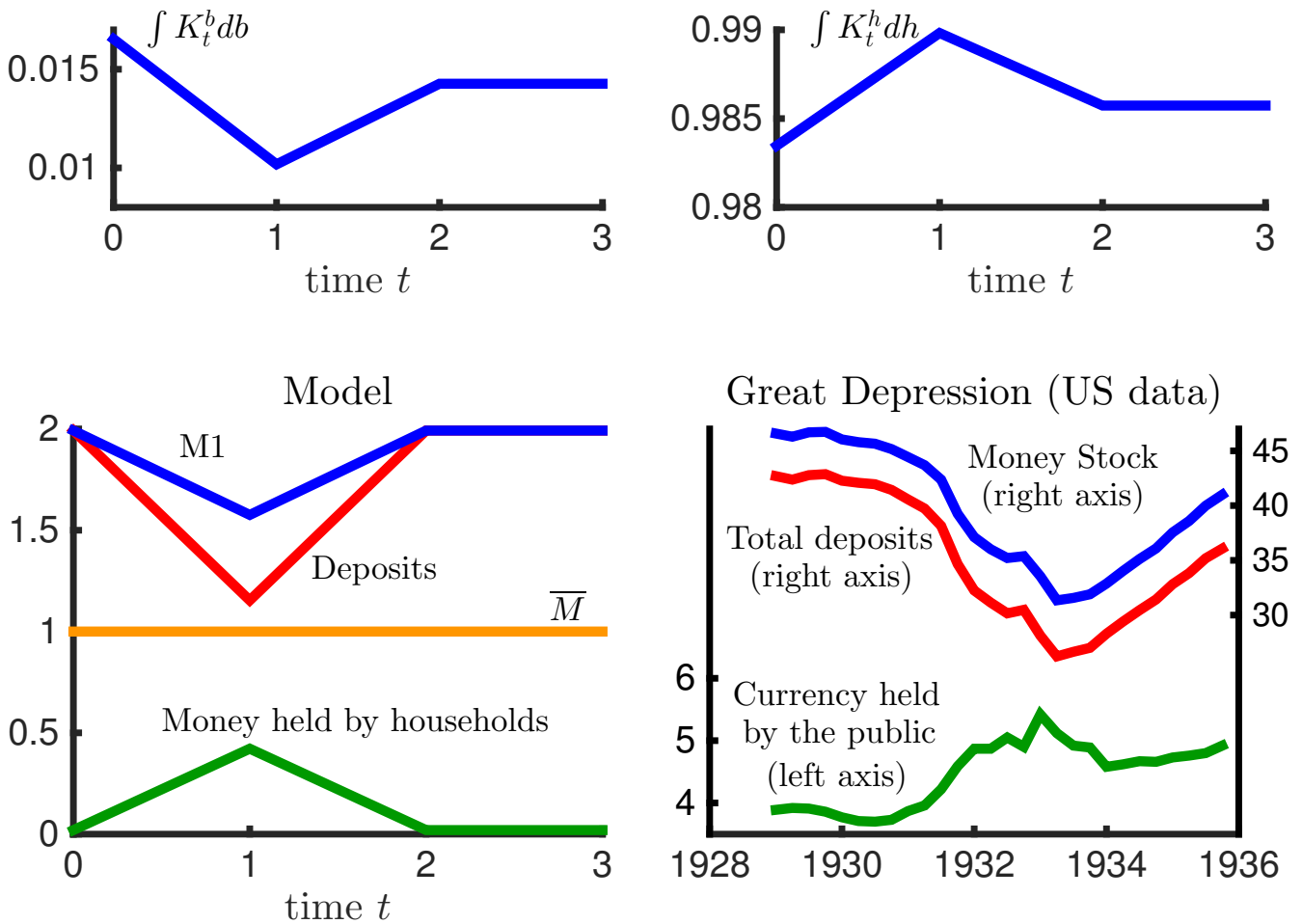

The economy experiences the crisis in period $t=1$ and reverts to normal in $t+1$. Top panel: prices (price level $p_{t}$, nominal price of capital $Q_{t}$ and return on capital $R_{t}^{K}$ ). Middle panel: stock of capital held by banks (left) and households (right) at the end of the day market. Bottom left panel: money market (money supply $\bar{M}$, deposits $\int_{\mathbb{H}} D_{t}^{h} d h$, money held by households $\int_{\mathbb{H}} M_{t}^{h} d h$, and $M 1=$ deposits + money held by households). Parameter values: see Table $2, \kappa=0.5$.

Bottom right panel: based on Table 2 from Friedman and Schwartz (1970) ("Money Stock" is the sum of currency held by the public and deposits); data are quarterly and seasonally adjusted, in billions of dollars. 
Figure 3: Multiplicity of bad equilibria
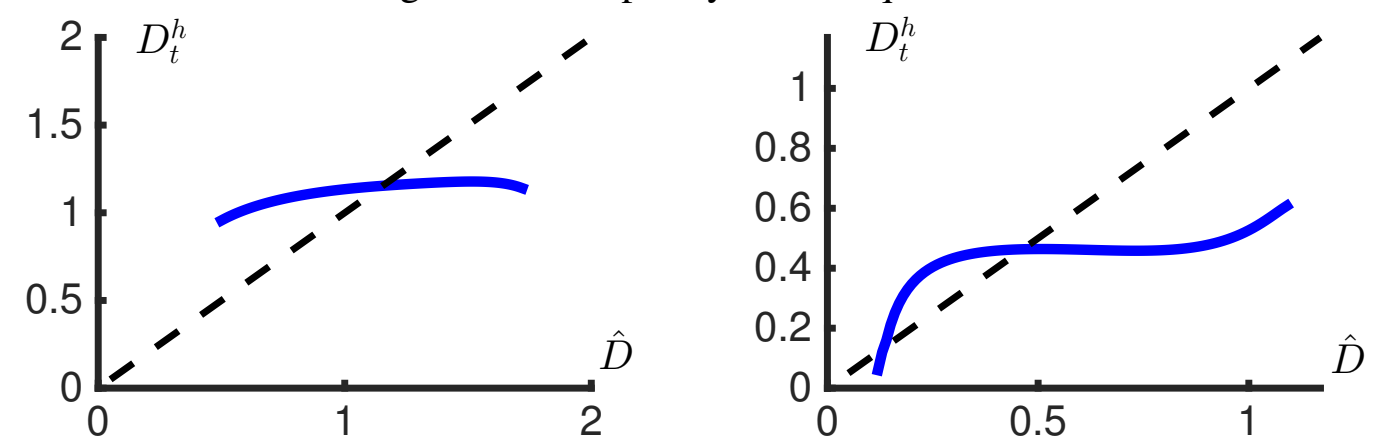

Left panel: $\kappa=0.5$; right panel: $\kappa=0.85$. The dashed line is the 45 degree line.

\subsection{Understanding the multiplicity of bad equilibria}

Proposition 4.2 suggests that the driving force behind the multiplicity of bad equilibria is a strategic complementarity across depositors. Recall that $\mathbb{H}(b)$ denotes the depositors of bank $b$, and thus $\int_{\mathbb{H}(b)} D_{t}^{h} d h=D_{t}^{b}$ is the amount of deposits of bank $b$.

Proposition 4.2. Taking prices $Q_{t}, p_{t}$, and $R_{t}^{K}$ as given, the actual return on deposits $r_{t}^{b}$ of bank $b$ with negative net worth $\left(N_{t}^{b}<0\right)$ satisfies $\frac{\partial r_{t}^{b}}{\partial D_{t}^{b}}>0$.

The proof is provided in Online Appendix C. To understand the result, recall that an insolvent bank $b$ has preexisting losses that must be borne by depositors holding deposits at bank $b$. Taking prices as given (in particular, $Q_{t}$ ), Proposition 4.2 fixes the value of the net worth $N_{t}^{b}<0$ (see equation (5)) which in turn represents the losses of the bank. If households decide to hold substantial deposits in bank $b$, each dollar of deposit bears a small loss; the opposite is also true. Consequently, the greater the deposits $\int_{\mathbb{H}(b)} D_{t}^{h} d h=D_{t}^{b}$ chosen by other depositors of bank $b$, the more willing household $h$ is to hold deposits issued by bank $b$, explaining the strategic complementarity. Such strategic complementarity does not arise in the good equilibrium because bank $b$ is solvent, and thus $r_{t}^{b}=R_{t}^{D}$ is independent of the choices of other depositors.

\footnotetext{
${ }^{22}$ In this context, the money multiplier is the ratio between $\mathrm{M} 1$ and $\bar{M}$.
} 
The result of Proposition 4.2 is a partial equilibrium exercise in the sense that it is derived fixing prices and analyzing the behavior of only one bank $b$ in the economy. Figure 3 shows how depositors affect each other's choices through a general equilibrium channel, computed as follows. First, fixing a value of deposits $\hat{D} \in\left(0, D^{*}\right]$, I force the representative household to hold deposits $\hat{D}$ (dropping the FOC with respect to $D_{t}^{h}$ ), and then I solve numerically for equilibrium prices $Q_{t}$, $p_{t}$, and the actual return $r_{t}(\underline{\psi})$. Second, I take as given the prices $Q_{t}, p_{t}$, and $r_{t}(\underline{\psi})$ just computed and allow a single household $h$ to take her optimal choices of money $M_{t}^{h}$, deposits $D_{t}^{h}$, and capital $K_{t}^{h}$ in a partial-equilibrium setting. Thus, I obtain a relation between $D_{t}^{h}$ and the value of $\hat{D}$. A fixed point that satisfies $D_{t}^{h}=\hat{D}$ is an equilibrium of the model.

Figure 3 plots the choices of deposit $D_{t}^{h}$ by the representative household $h$ as a function of $\hat{D}$. Two bad equilibria arise if $\kappa=0.85$, whereas only one bad equilibrium arises if $\kappa=0.5$. To understand this difference, recall that the maximization problem of banks (6) is subject to the non-negativity constraint $K_{t}^{b} \geq 0$. I argue that this constraint imposes a lower bound on the value of deposits $\hat{D}$ for which an equilibrium with runs on a fraction of the banking system exists. ${ }^{23}$ To see this, combine the non-negativity constraint $K_{t}^{b} \geq 0$ with the budget constraint (7), the decision rule of banks $M_{t}^{b}=\kappa D_{t}^{b}$ (from Proposition 3.1), the market clearing condition for deposits (23), and focus on a bank $b$ with negative net worth, $N_{t}^{b}=N_{t}(\underline{\psi})$, obtaining:

$$
\hat{D} \geq \frac{-N_{t}(\underline{\psi})}{1-\kappa}>0
$$

For the case $\kappa=0.5$, equation (27) is satisfied for $\hat{D} \geq 0.5$. Therefore it is not possible to fix a value of $\hat{D}$ lower than 0.5 to look for a deep crisis equilibrium. For $\kappa=0.85$, equation (27) is instead satisfied for $\hat{D} \geq 0.135$; the equilibrium value of deposits in the deep crisis equilibrium is 0.136 , so it satisfies the constraint (27).

The value of $N_{t}(\underline{\psi})$ is endogenous and thus (possibly) affected by monetary policy. In particular, monetary injections may reduce the absolute value of $N_{t}(\underline{\psi})$, thus relaxing the constraint (27). For $\kappa=0.5$, some monetary injections give rise

\footnotetext{
${ }^{23}$ See Online Appendix D for a discussion of the bankless crisis equilibrium, where the nonnegativity constraint on capital is binding.
} 
to a second bad equilibrium; see Sections 5.1.

When I solve the model with several values of the parameters, I can find at most two equilibria. It is not possible to rule out the existence of more than two bad equilibria using more general versions of the model, but understanding the multiplicity of bad equilibria in such models is beyond the focus of this paper.

\section{Monetary policy}

I consider the effects of a central bank that injects money into the economy during a crisis. The central bank announces a policy that will be implemented in the event of a panic, and can credibly commit to it. The central bank chooses money supply $M_{t+j}=\bar{M}\left(1+\mu_{t+j}\right)$ for $j=0,1,2, \ldots$ where $t$ is the period in which a crisis occurs. The full model with monetary injections is presented in Online Appendix F.

A monetary injection is characterized by two features. First, I distinguish between temporary and permanent increases in the money supply. A monetary injection is temporary if $\mu_{t}>0$ and $\mu_{t+1}=0$ (i.e., money reverts to the pre-crisis level when the panic ceases). A monetary injection is permanent if $\mu_{t+j}=\mu$ for all $j=0,1{ }^{24}$ Second, I distinguish between two methods to deliver the monetary injection: asset purchases and loans to banks.

In order to simplify the exposition, I further restrict Assumption 4.1 as follows.

Assumption 5.1. Assumption 4.1 holds, and equation (26) holds with equality.

A monetary injection creates inflationary pressure, counteracting the drop of nominal prices. Under Assumption 5.1, a sufficient condition to eliminate the bad equilibria is to inject enough money to achieve $Q_{t} \geq Q^{*}$. Alternatively, it is possible to define a threshold for the price level (rather than for $Q_{t}$ ) such that targeting $p_{t}$ above the threshold eliminates bad equilibria. A policy that achieves $p_{t} \geq p^{*}$ also achieves $Q_{t} \geq Q^{*}$, and it is thus sufficient to eliminate bad equilibria.

Note that relaxing Assumption 5.1 (i.e., allowing equation (26) to hold with strict inequality) let us to obtain similar results. A sufficient condition to eliminate

\footnotetext{
${ }^{24}$ I ignore the values of $\mu_{t+j}$ for $j>1$ because they do not affect the results.
} 
bad equilibria is to achieve $Q_{t}$ above a threshold, but in this case the threshold is lower than $Q^{*}$ and depends on initial conditions. Intuitively, if equation (26) holds with strict inequality, banks have a larger net worth and thus more buffer to counteract the effects of the panic. Therefore a smaller monetary injection is sufficient to eliminate bad equilibria.

While it is clear, under Assumption 5.1, that a sufficiently large monetary injection achieves $Q_{t} \geq Q^{*}$ and thus eliminates bad equilibria, the effects of a smaller monetary injection that results in $Q_{t}<Q^{*}$ are less clear. Does it eliminate bad equilibria? If not, what are the effects on the endogenous variables? A complete understanding of the positive implications of monetary injections requires analysis of these issues, independent of the optimality of policies. This analysis is also important if the central bank is unable or unwilling to achieve $p_{t} \geq p^{*}$ for any considerations not captured by the model. ${ }^{25}$

Sections 5.1 and 5.2 analyze monetary injections that result in $Q_{t}<Q^{*}$ under Assumption 5.1 (similar results are obtained relaxing Assumption 5.1 and using the relevant threshold for $Q_{t}$; see Online Appendix $\mathrm{G}$ for more discussion). I focus on temporary monetary injections, much like the policies implemented during the recent US financial crisis. ${ }^{26}$ Section 5.1 analyzes temporary monetary injections implemented using asset purchases, and Section 5.2 analyzes temporary monetary injections implemented using loans to banks.

Permanent monetary injections are discussed in Online Appendix H.

\footnotetext{
${ }^{25} \mathrm{New}$ Keynesian theory suggests that the optimal policy at zero nominal interest rates requires credibility to commit to future inflation (see, e.g., Krugman (1998) and Eggertsson and Woodford (2003)) and does not achieve the level of inflation that would prevail without the zero lower bound constraint. In practice, in the second half of 2008 , the zero lower bound became binding, and the US experienced some deflation despite massive monetary injections by the Federal Reserve.

${ }^{26}$ In testimony before the Committee on Financial Services of the U.S. House of Representatives, Bernanke (2010) suggests that the monetary expansions of the Federal Reserve are temporary: "In due course $[\ldots]$ as the expansion matures the Federal Reserve will need to begin to tighten monetary conditions to prevent the development of inflationary pressures. The Federal Reserve has a number of tools that will enable it to firm the stance of policy at the appropriate time."
} 


\subsection{Asset purchases}

The central bank buys capital in the market during the day of time $t$ and sells it during the day of $t+1$. Therefore money supply reverts to $\bar{M}$ after the crisis. The returns from holding capital are rebated to households in $t+1$.

For each level of $\mu_{t}$ implemented with asset purchases and resulting in $Q_{t}<Q^{*}$, Figure 4 displays the outcome of the most important endogenous variables. More results are provided in Online Appendix G. ${ }^{27}$ When the central bank buys capital on the market, the demand for capital rises, and therefore the price $Q_{t}$ is higher than it would be in an economy without intervention. Due to the monetary injection, more money is in circulation, and thus the price level $p_{t}$ is also higher.

The higher $Q_{t}$ has two counteracting effects on deposits. First, the higher price of capital reduces losses of insolvent banks. Consequently, the actual return on deposits $r_{t}(\psi)$ paid by insolvent banks is higher. This effect increases the demand for deposits from households since losses on deposits of insolvent banks are lower. Second, using the fact that the monetary injection is temporary and thus $Q_{t+1}=Q^{*}$, the nominal return on capital, equation (4), becomes:

$$
1+R_{t}^{K}=\frac{Q^{*}+Z p_{t}}{Q_{t}}
$$

The increase in $Q_{t}$ implied by the monetary injections reduces $R_{t}^{K}$ (recall from Section 4.2 that $p_{t} / Q_{t}$ is approximately constant, and thus the right-hand side of (28) is affected just by $Q^{*} / Q_{t}$ ). Since solvent banks pay the promised return on deposits $R_{t}^{D}=R_{t}^{K}$, the return $R_{t}^{D}$ declines with monetary injections as well. This effect reduces the demand for deposits by households, because $R_{t}^{D}$ is the return paid on deposits by solvent banks. The downward pressure on the demand for deposits is thus a consequence of the temporary nature of the monetary injection. In the numerical example that I consider, the higher the monetary injection $\mu_{t}$, the lower the deposits. ${ }^{28}$ (Amplification of the flight to liquidity arises also with loans to

\footnotetext{
${ }^{27}$ I use here the parameters in Table 2 and $\kappa=0.5$. The results are robust to the choices of other parameter values with an important caveat. For some values of the parameters, a bad equilibrium does not exist for some $\mu_{t}$. See Online Appendix G for more discussion.

${ }^{28}$ In an alternative calibration with $\kappa=0.2$, the equilibrium value of deposits increases with $\mu \in(0,0.5)$.
} 
Figure 4: Effects of monetary policy - Asset purchases
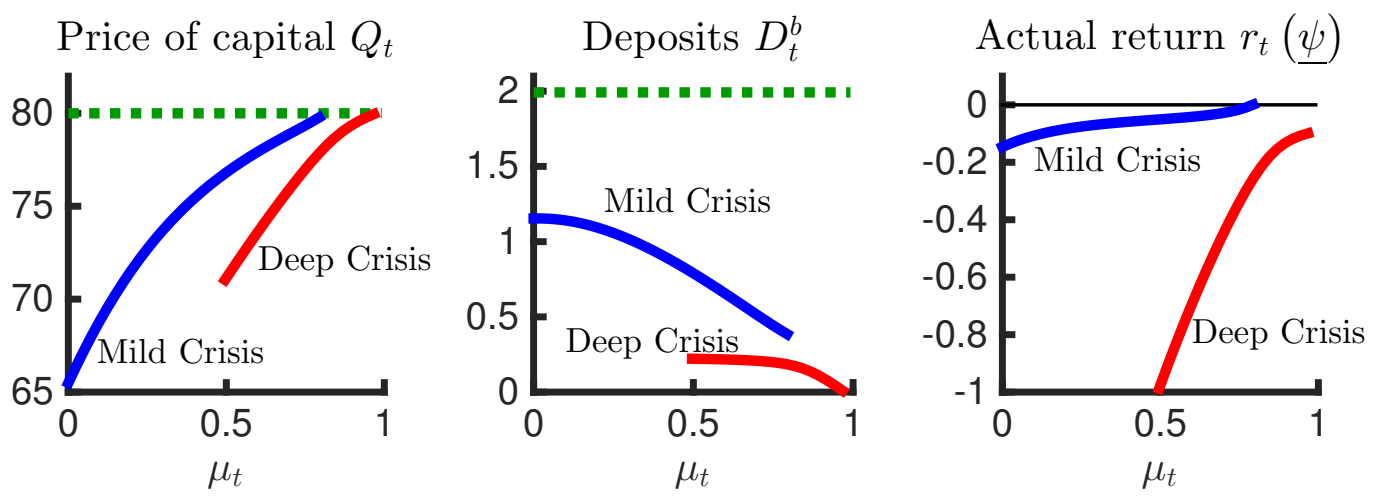

Horizontal axis: size of the monetary injection $\mu_{t}$. Vertical axis: price of capital $Q_{t}$ (left panel), deposit $D_{t}^{b}$ (mid panel), and actual return on deposits of insolvent banks $r_{t}(\underline{\psi})$ (right panel). The blue line represents the mild crisis equilibrium, the red line the deep crisis equilibrium, and the green dotted line the good equilibrium without monetary intervention. Parameter values: see Table $2, \kappa=0.5$.

banks that do not eliminate bad equilibria; see Figure 5.)

The effectiveness of monetary policy is reduced by exacerbation of the flight to liquidity. Recall that a necessary condition for a bad equilibrium is $r_{t}(\underline{\psi})<0$. On the one hand, monetary injections increase $Q_{t}$, which in turn reduces the losses of insolvent banks, and thus it increases $r_{t}(\underline{\psi})$. On the other hand, the reduction in deposits reduces $r_{t}(\underline{\psi})$ (as a consequence of Proposition 4.2). In the numerical example, $r_{t}(\underline{\psi})$ increases with $\mu_{t}$, but the reduction in deposits partially offsets the positive effect of the higher $Q_{t}$.

As discussed in Section 4.4, monetary injections affect the value of $N_{t}(\underline{\psi})$, thus reducing the right-hand side of equation (27). Therefore, for sufficiently large monetary injections, asset purchases give rise to a deep crisis equilibrium for $\kappa=$ 0.5 (see Figure 4), characterized by a larger flight to liquidity.

Can the central bank eliminate the bad equilibria using a temporary monetary injection implemented with asset purchases? Focusing on policies that result in $Q_{t}<Q^{*}$, the simulations show that there exists at least one bad equilibrium. 


\subsection{Liquidity facility: loans to banks}

The central bank provides loans to banks during the day at time $t$. For each dollar borrowed at time $t$, banks must repay $1+R_{t}^{K}$ dollars during the day in $t+1$. Banks can use funds borrowed from the central bank to hold money or buy capital. The budget constraint (7) of bank $b$ during the day becomes:

$$
K_{t}^{b} Q_{t}+M_{t}^{b} \leq D_{t}^{b}+(\text { loans from central bank })_{t}^{b}+N_{t}^{b} .
$$

If some banks are insolvent, I must consider the ability of the central bank to recover, in $t+1$, the loans made in the day at time $t$. At one extreme, suppose loans from the central bank are senior with respect to depositors. The central bank is able to recover the full value of loans, and depositors split the value of assets after the central bank is repaid. Proposition 5.2 states that this case is equivalent to Section 5.1 in which the central bank buys capital on the market. The result follows from the fact that the central bank does not bear any losses of insolvent banks in both cases. The proof is provided in Online Appendix C.

Proposition 5.2. Given a policy $\mu_{t}>0$ and $\mu_{t+j}=0$ for all $j \geq 1$ implemented with asset purchases, if there exists a bad equilibrium, then the same equilibrium exists in an economy in which the same policy is implemented using loans to banks with higher seniority than deposits.

I now focus on the other extreme case: loans from the central bank have the same seniority as deposits. The central bank faces the actual return $r_{t}(\underline{\psi})<0$ on loans to insolvent banks. In this case, a moderate monetary injection eliminates bad equilibria even if it achieves $Q_{t}<Q^{*}$; see Figure 5. Thus, achieving $Q_{t} \geq Q^{*}$ is sufficient but not necessary to eliminate the bad equilibria using this policy.

When loans to banks have the same seniority as deposits, households are willing to hold more deposits (than under asset purchases) because some of the losses of the insolvent banks will be borne by the central bank. This behavior of the household sector has two effect. First, from a partial equilibrium perspective, the actual return on deposits of insolvent banks $r_{t}(\underline{\psi})$ is higher and it turns positive for a moderate monetary injection (see right-hand panel of Figure 5, and see Proposition 4.2 for an 
Figure 5: Effects of monetary policy - Loans to banks
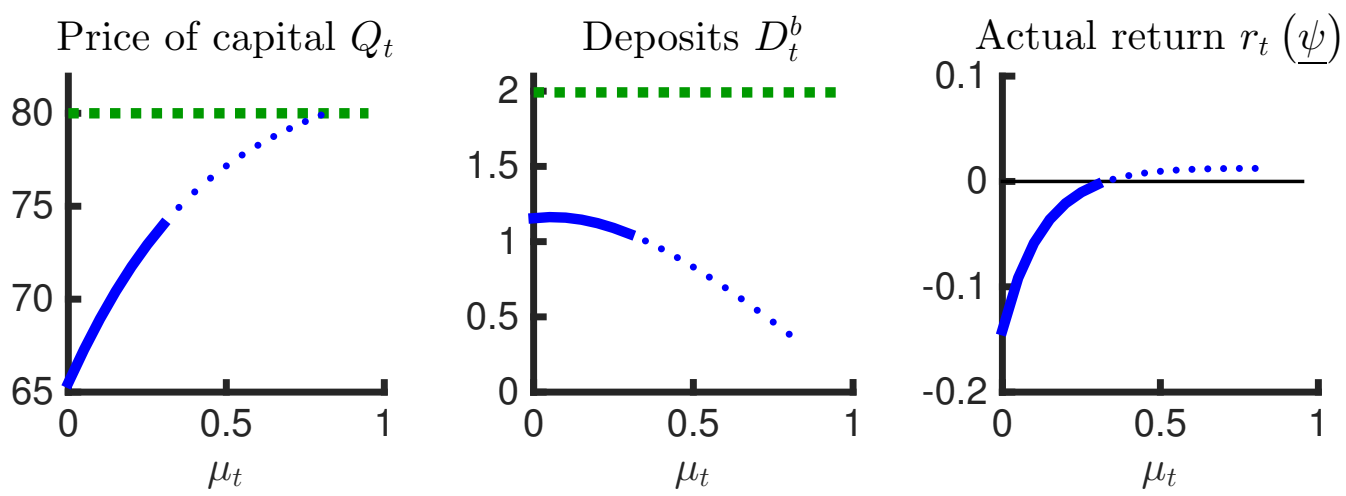

Horizontal axis: size of the monetary injection $\mu_{t}$. Vertical axis: price of capital $Q_{t}$ (left panel), deposit $D_{t}^{b}$ (mid panel), and actual return on deposits of insolvent banks $r_{t}(\underline{\psi})$ (right panel). In each subplot, the green dashed line is the good equilibrium without any monetary intervention, the blue solid line is the equilibrium value of the endogenous variables for which the monetary injection $\mu_{t}$ results in $r_{t}(\underline{\psi})<0$, and the blue dotted line is the candidate bad equilibrium for values of $\mu_{t}$ such that $r_{t}(\underline{\psi}) \geq 0$ (see Section 4.2). Parameter values: see Table $2, \kappa=0.5$.

explanation). Second, from a general equilibrium perspective, loans to banks break the strategic complementarity in the choice of deposits by the household sector, so only the mild crisis equilibrium exists. ${ }^{29}$

In the model, loans to banks are more effective than asset purchases at eliminating the bad equilibria. This is the case even restricting attention to the mild crisis equilibrium; loans to banks eliminate the mild crisis equilibrium if $\mu_{t}>0.3$, while asset purchases require much larger monetary injections ( $\mu_{t}>0.8$; see Figure 4$)$.

I leave to future research whether loans to banks is also a better policy in richer models, but I want to emphasize here an important case. In a model in which solvent banks are leveraged constrained, from a partial equilibrium perspective a bank might be unable to get a loan from the central bank without increasing leverage. ${ }^{30}$ Yet, loans to banks have two additional general equilibrium effects that contribute

\footnotetext{
${ }^{29}$ More precisely, if there exists two bad equilibria with a constant money supply $M_{t}=\bar{M}$, the strategic complementarity is weakened by a small monetary injection, but it disappears for a large enough $\mu_{t}$.

${ }^{30}$ In this model, I refer to leverage as the ratio of assets to net worth at the end of the day market.
} 
to reduce leverage. First, loans to banks are monetary injections that increase the equilibrium asset price $Q_{t}$, which in turn increases the net worth of banks. Second, as I discussed above, monetary injections may reduce deposits and thus assets (because banks invest a fraction of deposits into capital). In the numerical example of Figure 5, the general equilibrium effects prevail, and thus loans to banks reduce leverage in equilibrium.

\section{Conclusions}

I have presented a new framework to analyze bank runs in a dynamic, general equilibrium model, and I have used it to study unconventional monetary policy during panic-based financial crises. In some circumstances, loans to banks with the same seniority as deposits eliminate the bad equilibria, while asset purchases do not. Moreover, for some parameter values, if a temporary monetary injection does not eliminate the bad equilibrium, it amplifies the flight to liquidity.

In order to provide loans to banks with the same seniority as deposits, the central bank must have the (legal) ability to take a loss on a loan to a particular bank. Factors that influence credibility become crucial. For instance, in a more general model in which some banks are insolvent even in the good equilibrium (because of fundamental shocks), must the central bank take losses on such fundamentally insolvent banks in order to credibly commit to loans with the same seniority as deposits? The story suggested by these questions appears consistent with what occurred in 2008. The failure of Lehman Brothers in September 2008 might have communicated the inability of the Federal Reserve to make loans to banks facing risk of insolvency (contrary to what happened in March 2008 regarding Bear Stearns), thus opening up the possibility of a panic-based crisis.

This paper opens up three directions for future research. First, on the theoretical side, more work is required to identify the frictions that justify some of the assumptions that I have used, such as the nominal deposit contract. Second, on the empirical side, a richer version of the model would allow quantitative analysis in order to asses how panics, fundamental shocks, and other financial frictions

contribute to financial crises. Third, on the policy side, the framework that I have 
presented can be used to analyze other policies such as capital requirements and equity injections.

\section{References}

Akerlof, G. A. (1970). The market for "lemons": Quality uncertainty and the market mechanism. The Quarterly Journal of Economics, 488-500.

Allen, F., E. Carletti, and D. Gale (2013). Money, financial stability and efficiency. Journal of Economic Theory.

Alvarez, F., A. Atkeson, and P. J. Kehoe (2002). Money, interest rates, and exchange rates with endogenously segmented markets. Journal of Political Economy $110(1)$.

Andolfatto, D., E. Nosal, and B. Sultanum (2014). Preventing bank runs.

Angeloni, I. and E. Faia (2013). Capital regulation and monetary policy with fragile banks. Journal of Monetary Economics.

Armantier, O., E. Ghysels, A. Sarkar, and J. Shrader (2011). Stigma in financial markets: Evidence from liquidity auctions and discount window borrowing during the crisis. FRB of New York Staff Report 483.

Bernanke, B. S. (2010). Statement by Ben S. Bernanke, Chairman, Board of Governors of the Federal Reserve System, prepared for the Committee on Financial Services, US House of Representatives, February 10, 2010.

Bianchi, J. and S. Bigio (2013). Liquidity management and monetary policy.

Bigio, S. (2012). Financial risk capacity.

Boissay, F., F. Collard, and F. Smets (2013). Booms and systemic banking crises. Technical report, European Central Bank.

Brunnermeier, M. K. (2009). Deciphering the liquidity and credit crunch 20072008. Journal of Economic Perspectives 23(1), 77-100.

Brunnermeier, M. K. and Y. Sannikov (2011). The I Theory of money.

Caballero, R. and A. Krishnamurthy (2005). Financial system risk and flight to quality. National Bureau of Economic Research.

Caballero, R. J. and A. Krishnamurthy (2008). Collective risk management in a flight to quality episode. The Journal of Finance 63(5), 2195-2230. 
Carapella, F. (2012). Banking panics and deflation in dynamic general equilibrium. Christiano, L., R. Motto, and M. Rostagno (2003). The Great Depression and the Friedman-Schwartz Hypothesis. Journal of Money, Credit, and Banking 35(6).

Cooper, R. and D. Corbae (2002). Financial collapse: A lesson from the great depression. Journal of Economic Theory 107(2), 159-190.

Diamond, D. W. and P. H. Dybvig (1983). Bank runs, deposit insurance, and liquidity. The Journal of Political Economy 91(3), 401-419.

Diamond, D. W. and R. G. Rajan (2006). Money in a theory of banking. The American Economic Review 96(1), 30-53.

Duffie, D. (2010). The failure mechanics of dealer banks. The Journal of Economic Perspectives 24(1), 51-72.

Eggertsson, G. B. and M. Woodford (2003). Zero bound on interest rates and optimal monetary policy. Brookings Papers on Economic Activity 2003(1), 139-233.

Ennis, H. M. and T. Keister (2003). Economic growth, liquidity, and bank runs. Journal of Economic Theory 109(2), 220-245.

Fisher, I. (1933). The debt-deflation theory of great depressions. Econometrica: Journal of the Econometric Society, 337-357.

Freixas, X. and J. Rochet (2008). Microeconomics of Banking.

Friedman, M. and A. J. Schwartz (1963). A monetary history of the United States, 1867-1960. Princeton University Press.

Friedman, M. and A. J. Schwartz (1970). Monetary statistics of the United States: Estimates, sources, methods. NBER Books.

Gertler, M. and N. Kiyotaki (2013). Banking, liquidity and bank runs in an infinite horizon economy.

Gorton, G. and D. J. Mullineaux (1987). The joint production of confidence: Endogenous regulation and nineteenth century commercial-bank clearinghouses. Journal of Money, Credit and Banking 19(4), 457-468.

Gorton, G. B. (1988). Banking panics and business cycles. Oxford Economic Papers 40(4), 751-781.

Gorton, G. B. (2008). The panic of 2007. National Bureau of Economic Research.

Gorton, G. B. and A. Metrick (2012a). Securitized banking and the run on repo. Journal of Financial Economics 104(3), 425 - 451.

Gorton, G. B. and A. Metrick (2012b). Who ran on repo? National Bureau of 
Economic Research.

Green, E. J. and P. Lin (2003). Implementing efficient allocations in a model of financial intermediation. Journal of Economic Theory 109(1), 1-23.

He, Z., I. G. Khang, and A. Krishnamurthy (2010). Balance sheet adjustments during the 2008 crisis. IMF Economic Review 58(1), 118-156.

Ivashina, V. and D. Scharfstein (2010). Bank lending during the financial crisis of 2008. Journal of Financial Economics 97(3), 319-338.

Jovanovich, B. and V. Tsyrennikov (2014). Trading on sunspots.

Kiyotaki, N. and J. Moore (2012). Liquidity, business cycles, and monetary policy.

Krishnamurthy, A. (2010). Amplification mechanisms in liquidity crises. American Economic Journal: Macroeconomics 2(3), 1-30.

Krishnamurthy, A. and S. Nagel (2013). Interpreting repo statistics in the flow of funds accounts. Technical report, National Bureau of Economic Research.

Krishnamurthy, A., S. Nagel, and D. Orlov (2012). Sizing up repo.

Krishnamurthy, A. and A. Vissing-Jorgensen (2012). The aggregate demand for Treasury debt. Journal of Political Economy 120(2), 233-267.

Krugman, P. R. (1998). It's baaack: Japan's slump and the return of the liquidity trap. Brookings Papers on Economic Activity 29(2), 137-206.

Kubler, F. and K. Schmedders (2010). Tackling multiplicity of equilibria with Gröbner bases. Operations research 58(4-Part-2), 1037-1050.

Lagos, R. and R. Wright (2005). A unified framework for monetary theory and policy analysis. Journal of Political Economy 113(3), 463-484.

Lester, B., A. Postlewaite, and R. Wright (2012). Information, liquidity, asset prices, and monetary policy. The Review of Economic Studies 79(3), 1209-1238.

Lichtblau, D. (2000). Solving finite algebraic systems using numeric gröbner bases and eigenvalues. In Proceedings of the World Conference on Systemics, Cybernetics, and Informatics, Volume 10, pp. 555-560.

Lucas, R. E. (1990). Liquidity and interest rates. Journal of Economic Theory 50(2), 237-264.

Lucas, R. E. and N. L. Stokey (1987). Money and interest in a cash-in-advance economy. Econometrica, 491-513.

Lucas, R. E. and N. L. Stokey (2011). Liquidity crises. Economic Policy Paper 11-3,. Federal Reserve Bank of Minneapolis. 
Martin, A., D. Skeie, and E.-L. Von Thadden (2011). Repo runs.

Martinez-Miera, D. and J. Suarez (2012). A macroeconomic model of endogenous systemic risk taking.

Mattana, E. and E. Panetti (2014). A dynamic quantitative macroeconomic model of bank runs. Technical report.

Peck, J. and K. Shell (2003). Equilibrium bank runs. Journal of Political Economy 111(1), 103-123.

Telyukova, I. A. and L. Visschers (2013). Precautionary money demand in a business-cycle model. Journal of Monetary Economics 60(8), 900-916. 